NBER WORKING PAPER SERIES

\title{
CREDIBILITY AND POLICY CONVERGENCE: EVIDENCE FROM U.S. ROLL CALL VOTING RECORDS
}

\author{
David S. Lee \\ Enrico Moretti \\ Matthew J. Butler \\ Working Paper 9315 \\ http://www.nber.org/papers/w9315 \\ NATIONAL BUREAU OF ECONOMIC RESEARCH \\ 1050 Massachusetts Avenue \\ Cambridge, MA 02138 \\ October 2002
}

We thank David Card, John DiNardo, Hongbin Cai and Mel Hinich for helpful discussions, and David Autor, Anne Case, Dhammika Dharmapala, and participants of workshops at UNC-Chapel Hill, UTAustin, Chicago Economics and GSB, Princeton, and UCLA for comments and suggestions. We also thank Jim Snyder and Michael Ting for providing data for an earlier draft. We acknowledge the National Science Foundation (SES-0214351) for financial support. The views expressed herein are those of the authors and not necessarily those of the National Bureau of Economic Research.

(C) 2002 by David S. Lee, Enrico Moretti and Matthew J. Butler. All rights reserved. Short sections of text, not to exceed two paragraphs, may be quoted without explicit permission provided that full credit, including (C) notice, is given to the source. 
Credibility and Policy Convergence:

Evidence from U.S. House Roll Call Voting Records

David S. Lee, Enrico Moretti, and Matthew J. Butler

NBER Working Paper No. 9315

October 2002

JEL No. H0, K0

\begin{abstract}
Traditional models of politician behavior predict complete or partial policy convergence, whereby electoral competition compels partisan politicians to choose positions more moderate than their mostpreferred policies. Alternatively, if politicians cannot overcome the inability to make binding precommitments to policies, the expected result is complete policy divergence. By exploiting a regression discontinuity (RD) design inherent in the Congressional electoral system, this paper empirically tests the strong predictions of the complete divergence hypothesis against the alternative of partial convergence within the context of Representatives' roll call voting behavior in the U.S. House (1946-1994). The RD design implies that which party wins a district seat is quasi-randomly assigned among elections that turn out to be "close". We use this variation to examine if Representatives' roll call voting patterns do not respond to large exogenous changes in the probability of winning the election, the strong prediction of complete policy divergence. The evidence is more consistent with full divergence and less consistent with partial convergence, suggestive that the difficulty of establishing credible commitments to policies is an important real-world phenomenon.
\end{abstract}

David S. Lee

University of California, Berkeley

549 Evans Hall, \#3880

Berkeley, CA 94720-3880

and NBER

dslee@econ.berekely.edu
Enrico Moretti

Department of Economics

UCLA

405 Hilgard Avenue

Los Angeles, CA 90095-1477

and NBER

moretti@ucla.edu
Matthew J. Butler

University of California, Berkeley

549 Evans Hall, \#3880

Berkeley, CA 94720-3880

butler@econ.berkeley.edu 


\section{Introduction}

The central prediction of traditional models of electoral competition is that opposing politicians and parties, in the attempt to capture the "moderate" vote, are compelled to moderate their policy positions. The most well-known illustration of this notion is the result of the "median voter theorem" in the context of two-party political competition (Hotelling (1929) and Downs (1957)), whereby parties are forced to choose the same position. Most other models do not yield this stark prediction of complete convergence to the median voter. ${ }^{1}$ But they still predict partial policy convergence, whereby competition compels opposing sides to choose relatively more moderate positions than their respective "ideal" policies. ${ }^{2}$

On the other hand, as pointed out in Alesina (1988), any degree of policy convergence - whether complete or partial - requires that political parties have the ability to make binding pre-commitments to their announced positions, or to otherwise establish the credibility of their platforms (for example, via reputational mechanisms). Without credible commitments to moderate policies, voters have no choice but to expect that the party that wins the election will pursue its ex-post most-preferred policy. In this case, electoral competition fails to compel policy moderation; the result is complete policy divergence (Alesina 1988).

Which of these two contrasting perspectives is more empirically relevant? Does competition for moderate voters compel opposing politicians to moderate their policy positions to some degree? Or are politicians unable to credibly commit to anything other than the extreme party-line position? Existing studies typically reject the strong notion of complete policy convergence (e.g. the "median voter theorem" result). ${ }^{3}$ However, this leaves open the question of whether actual politicians' behaviors are better characterized by partial convergence or complete policy divergence. There is little empirical evidence on this question, and hence little evidence on whether the credibility problem in the context of two-party policy for-

\footnotetext{
$1 \quad$ Developments along the lines of Hotelling (1929) and Downs (1957) include (but are not limited to) Hinich, Ledyard, and Ordeshook (1972, 1973), McKelvey (1975), Wittman (1983), and Calvert (1985). Other examples of models that do not necessarily lead to complete convergence include Wittman (1977) Aldrich (1983), Coleman (1972), Baron (1994), and Grossman and Helpman (1996).

2 The literature is too large to be cited here. See Osborne (1995) for a nice review of variations of spatial competition under plurality rule. Also see Persson and Tabellini (2000).

3 For example, Poole and Rosenthal (1984) show that senators from the same state but from different political parties have different voting records. We discuss the existing literature in Section 5.
} 
mation is an important real-world phenomenon. The main empirical problem is that parties' most-preferred policy outcomes (hereafter referred to as their "bliss points") are unobservable to the researcher.

This paper empirically tests the hypothesis of complete policy divergence against the alternative of partial convergence in the context of explaining roll call voting patterns in the United States House of Representatives. In particular, we test the strong implication of complete policy divergence that exogenous shifts in the probability of a party winning the election in a particular district should have no impact on the positions of the parties' candidates for that district. Partial convergence (which is arguably more plausible than full convergence), on the other hand, predicts that an exogenous increase in the relative popularity of the Democrat's (Republican's) nominee in a particular district induces both candidates to adopt positions closer to the Democrat's (Republican's) bliss point.

Our test is based on a regression discontinuity $(\mathrm{RD})$ analysis of a quasi-experiment that is embedded in the Congressional electoral system. That is, we argue that among elections that were decided by a very narrow margin (say, by less than 1 percent of the vote), there is virtual random assignment of who - the Republican or Democratic nominee - wins the election. The test is based on a comparison of sharp RD and "fuzzy" RD (which we denote RD-IV) estimates of the degree of roll call voting divergence between opposing candidates in the U.S. House.

If the regression discontinuity design is valid, then the average voting records of Republicans who are barely elected will credibly represent, on average, how Republicans would have voted in the districts that were in actuality, barely won by Democrats (and vice versa). The difference between barely-elected Democrats' records and barely-elected Republicans' records - our benchmark regression discontinuity (RD) estimator - represents a credible estimate of the average policy divergence between the two parties across these districts. The RD estimator is consistent under both complete policy divergence and any degree of policy convergence.

On the other hand, the RD-IV estimate of the same gap between opposing parties' positions whereby we use, among close elections, who won the previous election as an instrument for which party wins the current election - is consistent only under full policy divergence, and inconsistent under partial 
policy convergence. This is because under full policy divergence, the outcome of an election has an impact on how the district's representative votes in Congressional sessions following the subsequent election only through its impact on which party wins the subsequent election - making the current election outcome a valid instrument. By contrast, under partial policy convergence, a Democrat (Republican) victory in a close election has an additional impact on the observed voting pattern of the district's representative in the subsequent Congressional session. By raising the probability of a Democratic (Republican) victory in the next election, it causes both candidates to shift their positions toward the Democrat's (Republican's) bliss point. Thus, as we show below, under partial policy convergence, the previous electoral outcome is not a valid instrument. As a result, full divergence predicts that the RD and RD-IV estimates will be similar (and consistent), and partial divergence predicts that they should be different.

Using roll call voting scores for the U.S. House of Representatives from 1946 to 1995, we report the following empirical results. First, we document that districts barely won by Democrats are similar to those barely won by Republicans along many pre-determined characteristics of the voting population. This lends credibility to the assumption upon which our analysis crucially rests: among closely-contested elections, who ultimately wins the seat is "as-good-as" randomly assigned. Second, our RD estimates reject the notion of full policy convergence, consistent with findings in the existing literature. We document that the degree of policy divergence is quite significant. In fact, barely-elected Democrats' (Republicans') voting records are just as liberal (conservative) as those of their colleagues who won their seats by landslide victories.

Our primary empirical result is that RD and RD-IV estimates of the voting record gaps are quite similar, and hence we fail to reject the strong, falsifiable prediction of the full policy divergence hypothesis. We use standard measures of voting records used in the literature (e.g. ADA scores), our own constructed measure of loyalty to the party leadership using the individual vote tallies on every issue voted on in the House, as well as other common political interest group voting scores (e.g. Chamber of Commerce, AFLCIO). All measures yield the qualitatively similar result. Furthermore, we conduct our analysis under two different assumptions: first, assuming that the policy gap between the two parties across all districts is the 
same, and second, allowing for unrestricted heterogeneity in the gap across districts. ${ }^{4}$ Both analyses point to evidence less consistent with partial convergence, and more consistent with the full policy divergence equilibrium.

Thus we find little empirical support, in this context, for the notion that electoral competition compels opposing candidates to moderate their policy positions - the central result of a large class of traditional models of political competition. On the other hand, the findings of complete policy divergence are perfectly consistent with the outcome that would occur if 1) politicians were unable to make credible commitments (via reputational mechansims or otherwise) to moderate their positions and 2) voters are forward-looking and have rational expectations - as suggested by Alesina (1988). We argue below that the U.S. House may be one of the most likely contexts in which reputational mechanisms can work to sustain partial convergence. Hence, the finding of "maximal" divergence in the context of voting in the U.S. House is suggestive that the difficulty of establishing credible commitments to policies is an important real-world phenomenon. Some recent models of representative democracy (e.g. Besley and Coate 1997, 1998) explicitly account for this, and assume that politicians are unable to credibly commit ex ante to policies more moderate than their ex post most-preferred policies. The evidence presented here provides empirical support for this modeling assumption.

The paper is organized as follows. Section 2 reviews the basic results of Alesina (1988) model of policy convergence. Section 3 describes inference problems encountered, and the strong predictions of the the complete divergence hypothesis. Section 4 reports the main results of the paper. We first test for full convergence. Having rejected full convergence, we conduct our tests of complete policy divergence, first adopting the assumption of homogeneity across districts, and then under a more general heterogeneous environment. We show that our results are robust to several alternative measures of roll call voting records. Section 5 discusses our findings in the context of other empirical studies on policy convergence, and Section

\footnotetext{
4 We consider the heterogeneous case because it can be argued that the IV estimate estimates a local average treatment effect (Imbens and Angrist, 1994) (see Hahn, Todd, and van der Klauww for the analogy of LATE in the case of regression discontinuities); hence, a difference in the RD and RD-IV estimates could be due to the different populations for which the treatment effect is estimated. However, as we show below, we can generate our RD benchmark estimate separately for the "always-takers", "nevertakers" and "compliers" (Angrist, Imbens, and Rubin 1995). This is only possible because we actually observe the underlying index that determines the treatment (which party wins the election).
} 
6 concludes.

\section{Background: Theory and Context}

In this section, we 1) outline the theoretical framework that we directly implement in our empirical analysis, and 2) discuss our choice of examining the context of roll call votes in the U.S. House.

\subsection{Theoretical Framework}

There are many ways in which the behavior of partisan politicians can be modeled (e.g. see Chapter 5 of Persson and Tabellini, 2000). However, we believe that the general framework of Alesina (1988) most directly highlights the issue of credible commitments and the sustainability of policy convergence via reputational mechansims. Furthermore, the model's level of parsimony makes it empirically tractable, and leads to testable implications. Since we adopt that framework, we begin by briefly reviewing its key features and the results that are most relevant to our analysis. Details of the model and justifications for its assumptions are found in Alesina (1988). ${ }^{5}$

For a given Congressional district, there are two political parties, party 1 and party 2. No distinction is made between the party and its nominee. ${ }^{6}$ Each party's preferences are defined over a single-dimensional policy space (e.g. characterizing how "liberal”/“conservative” the policy is), expressed as

$$
\begin{aligned}
& U(l)=-\sum_{t=0}^{\infty} \frac{1}{2} q^{t}\left(l_{t}-c_{1}\right)^{2} \\
& V(l)=-\sum_{t=0}^{\infty} \frac{1}{2} q^{t}\left(l_{t}-c_{2}\right)^{2}
\end{aligned}
$$

for party 1 and 2, respectively, with $c_{1}>c_{2}$ and $0<q<1$. $l_{t}$ is the chosen policy of the officeholder following election $t$, and $q$ is the per-election-cycle discount factor. These quadratic-loss functions imply that party 1's and 2's most preferred policies are $c_{1}$, and $c_{2}$, respectively. They are party 1's and 2's "bliss points".

Electoral outcomes themselves are not ex ante deterministic, but rather are characterized by a prob-

\footnotetext{
5 For convenience to the interested reader, we also adopt identical notation to Alesina (1988).

6 Alesina and Spear (1988) develop a model in which politicians are considered finite-lived, while parties are considered infinitelived. They show that in an overlapping-generations model, partially convergent equilibria are dynamically sustainable.
} 
ability function

$$
P_{t}=P\left(x_{t}^{e}, y_{t}^{e}, \delta_{t}\right)
$$

which denotes the probability that party 1 will win the district in election $t$. This function can be interpreted as capturing voters' own preferences regarding policy, and other characteristics of the parties. ${ }^{7} x_{t}^{e}$ and $y_{t}^{e}$ are the voters' (assumed rational) expectations of the policy that party 1's and 2's candidate, respectively, will adopt if elected. $\delta_{t}$ represents a non-policy determinant of this "vote production function", and parameterizes the popularity of a party's candidate, keeping expected positions constant. ${ }^{8}$ For example, it could represent the extent to which legislative experience is valued by voters. Voters are forward-looking and have rational expectations; that is, in equilibrium, their expectations of legislators' actions are correct. Thus, in the discussion below, it is assumed that in equilibrium party 1 chooses the policy $x_{t}=x_{t}^{e}$ and party 2 chooses $y_{t}=y_{t}^{e}$.

The most important assumption regarding the function $P$ is that a candidate's probability of winning the election rises, ceteris paribus, as her anticipated future policy choice moves "closer" to that of her opponent. ${ }^{9}$ This captures the notion of the (probabilistic) electoral benefit resulting from moving to the "middle" in order to capture more of the vote.

An uncertain electoral outcome implies that the implemented policy is also uncertain. The welfare of the party is assumed to be the expected utility

$$
\begin{aligned}
& w^{1}=P\left(x_{t}, y_{t}, \delta_{t}\right) U\left(x_{t}\right)+\left(1-P\left(x_{t}, y_{t}, \delta_{t}\right)\right) U\left(y_{t}\right) \\
& w^{2}=P\left(x_{t}, y_{t}, \delta_{t}\right) V\left(x_{t}\right)+\left(1-P\left(x_{t}, y_{t}, \delta_{t}\right)\right) V\left(y_{t}\right)
\end{aligned}
$$

for party 1 and 2, respectively.

The timing of elections is as follows. Before election $t$, candidates from each party announce how they will act (how they will vote on roll call votes), if elected. Voters form expectations of how each candidate will act immediately following the election. The election is held, and the winning party's

7 See Alesina (1988) for a more detailed discussion of how the function can be derived from voters' preferences.

8 Alesina (1988) does not use the notation $\delta_{t}$, but refers to such a factor in the text (when discussing exogenous shifts in $\bar{P}$ ), considering how an exogenous increase in the popularity of a particular party will alter the Nash bargaining solution. We introduce $\delta_{t}$ here to make the exposition clearer in a later section.

9 This is Assumption (iv) of Alesina (1988). 
candidate chooses a position ( $x_{t}$ for party 1 , and $y_{t}$ for party 2 ). The voters' rational expectations of the candidates' choices turn out to be correct. The electoral cycle then repeats.

The key results from Alesina (1988) are:

1. The efficient outcome is one where $x_{t}=y_{t}$ - full convergence. ${ }^{10}$ Because of the concavity of the preference functions, both parties prefer a moderate outcome with certainty to a "fair" bet.

2. In a one-period game, without the possibility of binding pre-commitments to policies, candidates' announcements are not credible, and candidates, if elected, choose their bliss points, as expected by voters. The basic problem is that once elected, candidates have every incentive to move to the most-preferred policy, and face no recourse from deviating from an announced policy. Rational voters expect that and vote accordingly. The inability of candidates to make binding pre-commitments leads to the complete divergence result. Thus, policy convergence results require some way to overcome this inability to pre-commit; otherwise the equilibria will be time-inconsistent. This equilibrium is inefficient.

3. In a repeated-game context, fully convergent equilibria can be sustained as long as the discount factor is sufficiently high. The proposed equilibrium is one in which parties agree to announcing, and carrying out a moderate outcome if elected. The expectation is that if the legislator deviates from the announced policy, the party (having lost its reputation) reverts to the bliss point forever, and the opposing party would also revert to its bliss point. As long as the discounted threat of "punishment" outweighs the short-term gains from "cheating", the full convergence sub-game perfect equilibrium can be sustained.

4. Even when the fully-convergent equilibria cannot be sustained, as long as the discount factor is not zero, partially convergent equilibria are still sustainable under the same kind of reputational mechanism. That is, the electoral benefit to capturing "middle voters" leads to both parties to moderate their positions, which is Pareto superior (from the perspective of the parties) to the fully divergent one-shot Nash outcome.

5. In an infinitely repeated game context, if discount factors are sufficiently high, there are multiple equilibria. Fully-convergent, "median-voter-type" equilibria are sustainable, as are partially convergent equilibria. In addition, the full policy divergence result also remains an equilibrium of the dynamic game.

The strong prediction of the full divergence equilibrium $\left(x_{t}=c_{1}, y_{t}=c_{2}\right.$ for all $\left.t\right)$ is that an exogenous change in the probability of a party winning the election should have no impact on the positions taken by the two parties. Essentially, politicians are unable to overcome the credibility problem, and hence parties always choose their bliss points irrespective of their relative popularity, because any move to the middle is not credible. This is the central prediction on which we base our empirical test.

In order to assess the power of our test against alternative hypotheses, it is instructive to consider how an exogenous change in the probability of winning would affect policy positions under three alternative cases.

10 By "efficient", Alesina (1988) refers exclusively to the welfare of the political parties, not the voters. We adopt his notion here. See Besley and Coate $(1997,1998)$ for a detailed discussion of the notion of "efficiency" in models of representative democracy. 
Case 1: Full Convergence. There is even a multiplicity of Pareto-optimal points on the fullyconvergent efficient frontier. Alesina (1988) uses Nash bargaining to choose one point, and proves an intuitive result: the Nash-bargaining solution moves towards party 1's bliss point with an exogenous increase in party 1's popularity. That is, ceteris paribus, the equilibrium $x_{t}=y_{t}$ moves towards $c_{1}$ in response to an increase in $P_{t}$. The intuition is that party 1's bargaining position is strengthened by an exogenous increase in its popularity.

Case 2: Partial Convergence; binding pre-commitments possible. A similar intuitive comparative static holds even in the one-shot Nash Equilibrium with binding pre-commitments to policies. The static game does not yield full convergence or full divergence, but does yield partial convergence (Calvert 1985, Alesina 1988). We show in the Appendix that, under some regularity conditions, the model predicts that an exogenous increase in the relative popularity of party 1 (party 2) results in the equilibrium moving towards party 1's (party 2's) bliss point.

Case 3: Partial Convergence; binding pre-commitments not possible. A similar comparative static for the partially convergent case supported by reputation has not been established, although Alesina (1988) proves existence of such sustainable partially convergent equilibria, when $q>0$. However, since the constraints of individual rationality and sub-game perfection both explicitly depend upon the probability that a party wins the election, one would expect the equilibrium policy positions of both parties to move in response to a large exogenous change in the relative odds of winning the election. It is important to note that in this case, if $c_{1}$ and $c_{2}$ are unquantifiable/unobservable to the researcher and if there is no clear theoretical prediction about what direction an exogenous increase in $P_{t}$ would impact equilibrium positions, then the notion of partial convergence has no empirical content. This is because in this parsimonious model, there are only 3 exogenous factors, $c_{1}, c_{2}$, and $\delta$. Without a comparative static result for a change in $\delta$, the partially convergent and fully divergent equilibria would be empirically indistinguishable, even though they have significantly different welfare implications.

In light of Case 3, the finding that candidates do not respond to changes in the probability of winning would be consistent with both full divergence and partial convergence if the nature of the partially 
convergent equilibrium was such that there was no systematic effect of a change on the probability of winning on the candidates' positions. However, if the partially convergent equilibrium is unresponsive to such exogenous changes in probabilities, then there would be no empirical content to the partially convergent hypothesis. Thus, we believe it reasonable to stipulate that even in Case 3, any meaningful notion of partial convergence would require that an exogenous change in the relative popularities of the two parties will cause the equilibrium positions to move in some direction. In particular - in light of the comparative static in Case 2, which mirrors the comparative static of Case 1 - one might expect that an exogenous increase in the relative popularity of party 1 to move the equilibrium towards party 1's bliss point.

\subsection{Context: Roll Call Votes in the U.S. House}

Given the wide range of possible equilibria, it would be informative to obtain evidence on which of the three types of equilibria is most empirically relevant for describing the policy formation mechanism in a major, long-standing representative democracy, such as the United States. In particular, we believe that the U.S. House of Representatives is an ideal context for testing full policy divergence against the alternative of partial convergence for a number of reasons.

First, the U.S. federal legislative body is virtually a two-party system, and the notion of policy convergence is frequently modeled in a two-party context. When there are more than two candidates, the basic insight of the Hotelling (1929) and Downs (1957) approach to policy convergence is somewhat weakened (see Osborne 1995). Furthermore, it is widely accepted that Democrats and Republicans have different (and often directly opposing) "ideal" policy positions. Indeed, existing empirical studies show that party affiliation is one of the strongest predictors of roll call voting patterns. ${ }^{11}$ Therefore, it is meaningful to ask whether electoral competition compels opposing parties' nominees to moderate their positions in the face of strong incentives to vote along party lines. If the U.S. House were a relatively non-partisan environment (with "bliss points" relatively close together), the distinction between full policy divergence and partial convergence would be less important, and a test to distinguish between them less useful.

Second, elections to the U.S. House are of the plurality/winner-take-all type. The election yields

11 See Section 5. 
one distinct legislator, who in principle, represents the interests of that district. This exactly matches the theoretical framework described above. By contrast, examining the U.S. Senate - where there are two representatives for each state - would be less appropriate given the theoretical framework that we adopt. Furthermore, in the U.S. House, electoral competition occurs separately at each Congressional district. This more closely matches the conceptual framework described above, compared to, for example, proportional representation systems, whereby seats are allocated in proportion to the national vote.

Third, there are reasons why reputational mechanisms are more likely to be relevant for elections to the U.S. House, compared to elections to other political offices. U.S. House elections are held every two years, and there are no term limits (as opposed to gubernatorial and presidential elections), meaning that political careers can consist of several terms in office. Furthermore, political tenure in the House is often a stepping-stone to participating in electoral races for higher offices. For these reasons, it is plausible that candidates for the U.S. House have high discount factors, which allows reputation to support partially convergent equilibria. The conjecture that candidates have high discount factors is perhaps less supportable in other political environments, with longer election cycles (e.g. the Senate) or term-limits (e.g. U.S. Presidency or Governorship in the states with term-limits).

Our empirical tests focus on Representatives' voting records. On the one hand, quantifying how representatives vote requires a certain degree of subjectivity, and it is difficult to associate monetary values to particular votes. On the other hand, the "ideal" measures - individual candidates' positions on tax rates or expenditure levels - are strictly unobservable to the researcher. Representatives' roll call votes are directly observable, and are part of the public record, implying that in principle, voters can compare a legislator's record to their platforms and promises as candidates (and opponents can advertise any deviations during election campaigns). Convergent equilibria of the kind described in Alesina (1988) requires that policy positions are perfectly observable by voters and that it can be determined whether politicians deviate from those policy positions.

Finally, the examination of close votes is particularly appropriate in this context. Our main motivation for examining close elections is that such an analysis isolates "near-random" assignment of which 
party wins the seat. But an added benefit from this focus is that moderation of policy positions is more likely to occur in "moderate" districts - where there is roughly equal probability of each party winning the election (Alesina 1988).

In sum, we believe that the context of roll call voting behavior of representatives who were barely elected to the U.S. House is an ideal setting to test full policy divergence against partial convergence because: 1) the degree of partisanship in the U.S. House implies that there is a meaningful difference between the two types of equilibria, and 2) based on the theoretical framework reviewed in the previous section, there are many reasons to believe that reputational mechanisms would be able to sustain some degree of policy convergence between opposing candidates in the U.S. House.

\section{Empirical Problems and Implications}

In this section, we describe two empirical problems which stand in the way of empirically distinguishing between fully convergent, partially convergent, and fully divergent equilibria. We then describe how we use a regression discontinuity design to address these problems.

\subsection{Unobservable policy positions and bliss points}

The first important problem is that although the announced and expected positions of both opposing candidates are known to voters in each district, as researchers, we can only systematically measure the actions of the legislator. More specifically, in our analysis, we focus on the roll call voting behavior of the legislator, which we can observe and quantify. But we do not observe and cannot quantify what the losing candidate's roll call voting behavior would have been, had he won the election instead.

More formally, adding the subscript $i$ to denote the Congressional district, we only observe

$$
R C_{i t}=\left\{\begin{array}{l}
x_{i t} \text { if party } 1 \text { wins election } t \\
y_{i t} \text { if party } 2 \text { wins election } t
\end{array}\right.
$$

which can be equivalently written as

$$
R C_{i t}=y_{i t}+D E M_{i t}\left(x_{i t}-y_{i t}\right)
$$

where $R C_{i t}$ is a measure of district $i$ 's legislator's roll call voting behavior - for example, how liberal 
the voting record is - in the Congressional session that follows election $t . D E M_{i t}=1$ if party 1 (e.g. Democrats) wins election $t$ in district $i$, and 0 if party 2 (e.g. Republicans) prevails. As researchers, we cannot measure both positions simultaneously, so it is impossible to know, for a particular district, if $x_{i t}$ equals (e.g. full convergence) or substantially deviates (e.g. full divergence) from $y_{i t}$.

The second problem is that it is difficult to obtain credible measures of the bliss points of parties in any given district (denote the district-time-specific bliss points for party 1 and 2 as $c_{1 i t}$ and $c_{2 i t}$, respectively). ${ }^{12}$ This makes it impossible to assess whether or not $x_{i t}=c_{1 i t}\left(y_{i t}=c_{2 i t}\right)$, which is, by definition, what differentiates a partially convergent equilibrium from the fully divergent case.

Existing empirical studies implicitly or explicitly estimate a specification in the form of 5: a regression of $R C_{i t}$ (ADA scores for the House Representative) on some proxy for voters' "preferences" (e.g. the Democratic presidential vote share in the district as a measure of how liberal the district is) and the dummy variable $D E M_{i t}$. It is clear from Equation 5 that as long as the measure for preferences is an adequate measure for $y_{i t}$, and which party wins the seat $\left(D E M_{i t}\right)$ is independent of those preferences, the full convergence hypothesis $-E\left[x_{i t}-y_{i t}\right]=0$ - can be tested by examining the coefficient on the party affiliation, $D E M_{i t}$. Indeed, the existing literature finds evidence strongly inconsistent with the full policy convergence hypothesis. ${ }^{13}$

On the other hand, this regression approach cannot differentiate between full policy divergence and some degree of policy convergence. In particular, the regression coefficient on $D E M_{i t}-E\left[x_{i t}-y_{i t}\right]$ - can either be equal to $E\left[c_{1 i t}-c_{2 i t}\right]$ (full divergence), or be much smaller than $E\left[c_{1 i t}-c_{2 i t}\right]$ (partial convergence). The coefficient on the proxy for voters' preferences is not informative about the degree of partial convergence; rather it indicates whether the district-specific "bliss points" of the parties, $c_{1 i t}$ and $c_{2 i t}$, are larger - more liberal - if the proxy for "liberalness" is higher, which we might expect when examining the cross-section of Congressional districts. That is, we might expect that the bliss point for a Republican nominee in Massachusetts would be relatively more "liberal' compared to bliss point for a Republican

\footnotetext{
12 For example, leaders of Democrats in Alabama may have ideal positions quite different from the Democratic leadership in Massachusetts.

13 For a discussion of empirical regularities in the literature, see Snyder and Ting (2001a).
} 
nominee in Texas.

\subsection{Identification Strategy: RD versus RD-IV Estimates}

\subsubsection{Benchmark RD Estimate}

Our test of full divergence against the alternative of (partial or full) policy convergence is based on the comparison between sharp regression discontinuity (RD) and fuzzy RD (which we refer to as RD-IV) estimates of the degree of policy divergence between candidates of opposing parties, averaged across Congressional districts.

We begin by showing how a regression discontinuity (RD) design inherent in the electoral system directly addresses the first empirical problem discussed above. In particular, we argue that districts in which candidates for party 1 (e.g. Democrats) are barely elected (say, by a tiny fraction of the vote) are ex ante similar to districts in which candidates for party 2 (e.g. Republicans) are barely elected. In particular, if the regression discontinuity design is valid, the two groups of districts would be similar, along all predetermined characteristics, including the voters' preferences, and the parties' district-specific bliss points. This virtual "random assignment" of which party wins a close election implies that the average voting records of Republicans that are barely elected can credibly represent, on average, how Republicans would have voted in the districts that were in reality, barely won by Democrats (and vice versa).

To see how the regression discontinuity design addresses the inference problem, first note that we can express $P_{i t}=P\left(x_{i t}^{e}, y_{i t}^{e}, \delta_{i t}\right)$ in terms of the vote share for party 1 (Democrats):

$$
V S_{i t}=v s\left(x_{i t}^{e}, y_{i t}^{e}, \delta_{i t}, \varepsilon_{i t}\right)
$$

where $\varepsilon_{i t}$ is an unpredictable and unforecastable component of the vote share that is independent of all other factors. This could be interpreted as turn-out on voting day, or errors in polls, etc. ${ }^{14}$ vs is a continuously differentiable function, and the framework presented in the previous section implies that the partial derivatives have the following signs: $v s_{1}<0, v s_{2}<0$; we normalize $v s_{3}>0$ and $v s_{4}>0$. In a two-party system, $D E M_{i t}=1$ if and only if $V S_{i t}>\frac{1}{2}$.

14 The existence of this component is equivalent to Alesina's (1988) maintained assumption that electoral outcomes are uncertain. 
In any equilibrium (full divergence, partial convergence, or complete convergence), the positions of candidates in district $i$ for election $t$ are completely determined by the bliss points and the voting production function, so that $x_{i t}=m^{x}\left(c_{1 i t}, c_{2 i t}, \delta_{i t}\right)$ and $y_{i t}=m^{y}\left(c_{1 i t}, c_{2 i t}, \delta_{i t}\right)$. We assume throughout that $m^{x}$ and $m^{y}$ are continuously differentiable with respect to their arguments.

The simple difference between the voting records of Democratic and Republican legislators is uninformative about the full policy convergence hypothesis. This is because

$$
\begin{aligned}
& E\left[R C_{i t} \mid D E M_{i t}=1\right]-E\left[R C_{i t} \mid D E M_{i t}=0\right] \\
= & E\left[m^{x}\left(c_{1 i t}, c_{2 i t}, \delta_{i t}\right) \mid V S_{i t}>\frac{1}{2}\right]-E\left[m^{y}\left(c_{1 i t}, c_{2 i t}, \delta_{i t}\right) \mid V S_{i t}<\frac{1}{2}\right] .
\end{aligned}
$$

There is potential for serious selection bias, as $c_{1 i t}, c_{2 i t}$, and $\delta_{i t}$ all help determine $V S_{i t}$, and hence the outcome of the election. Intuitively, the districts that were won by Democrats are likely to be systematically different from those won by Republicans. In particular, it is plausible (and likely) that voters in districts won by Democrats are, on average, more liberal than voters in districts won by Republicans; it is also plausible that both parties' bliss points are more liberal in relatively more liberal districts. The source of the problem is that the distribution of $c_{1 i t}, c_{2 i t}$, and $\delta_{i t}$ within Democratic-won districts is quite likely to be very different from that within Republican-won districts.

Under a mild continuity assumption, if the attention is restricted to elections where the vote share margin of victory is slim, the Democrat and Republican districts will become arbitrarily similar in the distribution of these quantities.

Proposition 1 If $c_{1 i t}, c_{2 i t}, \delta_{i t}$, and $\varepsilon_{i t}$ have continuous joint density, then the density of $c_{1 i t}$, $c_{2 i t}$, and $\delta_{i t}$ conditional on $V S_{i t}=\frac{1}{2}+\Delta$ equals the density conditional on $V S_{i t}=\frac{1}{2}-\Delta$ in the limit, as $\Delta \rightarrow 0$.

This is an important result for the empirical analysis in the paper, which focuses on the comparison of barely-elected Democrat and Republican districts. Essentially, it implies that when examining "close" elections, there is "as-good-as" random assignment of which party ultimately wins. In the closest of elections (e.g. decided by 1 vote), which party wins is determined as if by the flip of a coin. This will result in the bare-Democrat and bare-Republican districts being on average similar in all the characteristics that determine the vote share. 
It follows that

$$
\begin{aligned}
& E\left[R C_{i t} \mid V S_{i t}=\frac{1}{2}+\Delta\right]-E\left[R C_{i t} \mid V S_{i t}=\frac{1}{2}-\Delta\right] \\
\approx & E\left[m^{x}\left(c_{1 i t}, c_{2 i t}, \delta_{i t}\right)-m^{y}\left(c_{1 i t}, c_{2 i t}, \delta_{i t}\right) \mid V S_{i t}=\frac{1}{2}\right] \\
= & E\left[x_{i t}-y_{i t} \mid V S_{i t}=\frac{1}{2}\right]
\end{aligned}
$$

for $\Delta$ sufficiently small.

So this regression discontinuity $(\mathrm{RD})$ estimand - the comparison of voting patterns between barelyelected Democrats and barely-elected Republicans - should equal the average difference in policies between opposing candidates in those districts. Under full policy convergence, this quantity should be zero. Under full divergence, it is $E\left[c_{1 i t}-c_{2 i t} \mid V S_{i t}=\frac{1}{2}\right]$, and under partial convergence, the RD estimand is less than $E\left[c_{1 i t}-c_{2 i t} \mid V S_{i t}=\frac{1}{2}\right]$, but greater than zero. Most importantly, the quantity $E\left[x_{i t}-y_{i t} \mid V S_{i t}=\frac{1}{2}\right]$ is consistently estimated by the RD gap under full convergence, partial divergence, and full divergence.

\subsubsection{Differentiating between Complete Divergence and Partial Convergence}

The bliss points $c_{1 i t}$ and $c_{2 i t}$ are not easily measured by the researcher, which makes a simplistic test of full policy divergence - a comparison between $E\left[x_{i t}-y_{i t} \mid V S_{i t}=\frac{1}{2}\right]$ and $E\left[c_{1 i t}-c_{2 i t} \mid V S_{i t}=\frac{1}{2}\right]-$ infeasible. However, as mentioned in Section 2 the theoretical framework generates a strong prediction for the full policy divergence hypothesis. Specifically, in the fully divergent equilibria (where $x_{i t}=c_{1 i t}$ and $y_{i t}=c_{2 i t}$ ) an exogenous change in the probability of a Democrat (Republican) victory should not cause a change in the parties' positions, because those policy positions are completely determined by the exogenously determined "bliss points". An exogenous change in the relative popularity of a party in any given district should only have the effect of altering the relative odds of whether party 1's or 2's bliss point is ultimately chosen. Formally, the partial derivatives $m_{3}^{x}=m_{3}^{y}=0$, but $v s_{3}>0$.

And as mentioned above, this stark prediction does not hold for the fully convergent or partially convergent equilibrium. For Case 1 and Case 2, $m_{3}^{x}>0$, and $m_{3}^{y}>0$. And as argued earlier, given that researchers cannot observe $c_{1 i t}$ and $c_{2 i t}$, any meaningful notion of partial convergence in Case 3 requires that $m_{3}^{x} \neq 0, m_{3}^{y} \neq 0$. 
In our analysis, we use the notion that party incumbency causes an exogenous increase in the probability of winning the subsequent election for testing the full divergence hypothesis. Lee $(2001,2002)$ argues that the regression discontinuity estimate

$$
E\left[D E M_{i t} \mid V S_{i t-1}=\frac{1}{2}+\Delta\right]-E\left[D E M_{i t} \mid V S_{i t-1}=\frac{1}{2}+\Delta\right]
$$

represents a valid estimate of the causal party incumbency effect. Lee $(2001,2002)$ finds that, winning an election causes an increase in the probability that the party will win the next election as much as 0.45 .

Thus, our test of full divergence amounts to assessing whether the party winning an election - by causing it have a greater probability of winning the next election - causes it to change its policy position for the next election, all else equal. The regression discontinuity design is helpful here because it arguably generates as-good-as randomized variation in whether or not a party wins an election, and hence keeps all else equal (on average).

Proposition 2 If $D E M_{i t-1}$ has an average causal effect on $D E M_{i t}$ (there exists a true electoral advantage to party incumbency) then DEM $M_{i t-1}$ has an impact on $\delta_{i t}$.

This follows immediately from the fact that $D E M_{i t}$ is a known, deterministic function $\left(D E M_{i t}=\right.$ 1 if and only if $V S_{i t}>\frac{1}{2}$ ) of $V S_{i t}$, so anything that causally effects $D E M_{i t}$ must do so by impacting $V S_{i t}$. With the theoretical framework of Section 2, the equilibrium values of $V S_{i t}$ are completely determined by $c_{1 i t}, c_{2 i t}, \delta_{i t}$, and $\varepsilon_{i t}$. Bliss points are exogenously determined, and $\varepsilon_{i t}$ is assumed to be the unpredictable component that generates the uncertain electoral outcome; hence $D E M_{i t-1}$ must induce an impact on $D E M_{i t}$ through effecting $\delta_{i t}$.

While there are many interpretations of what $\delta_{i t}$ could represent, one concrete example is that it represents the voters' (independent from any partisan preferences) valuation of experience in Congress. With this interpretation, an incumbent party has a higher probability of winning the seat again because the expected experience level of its candidate will be higher than the expected challenger (Lee 2001).

Test under Homogeneity Before turning to a more general model with unrestricted heterogeneity, we illustrate the basic intuition of the test by starting with the simplifying assumption that the difference be- 
tween opposing parties' positions is constant across districts. In other words, even though $x_{i t}, y_{i t}$ varies across districts, $x_{1 i t}-y_{2 i t}=k_{0}$ is constant across districts.

Proposition 3 Under homogeneity, if 1) whether or not a Democrat held the seat in election $t-1$ (DEM $\left.M_{i t-1}\right)$ is as-good-as randomly assigned, and 2) DEM $M_{i t-1}$ has a nonzero impact on DEM $M_{i t}$, then only the complete divergence hypothesis implies that $D E M_{i t-1}$ is a valid instrument for estimating $k_{0}$, the impact of $D E M_{i t}$ on $R C_{i t}$. If the complete divergence hypothesis is not true $D E M_{i t-1}$ is not a valid instrument.

To see this, note that Equation 5 can be re-written as

$$
R C_{i t}=m^{y}\left(c_{1 i t}, c_{2 i t}, \delta_{i t}\right)+D E M_{i t} k_{0}
$$

Under the hypothesis of complete divergence $m^{y}\left(c_{1 i t}, c_{2 i t}, \delta_{i t}\right)=c_{i 2 t}$. As mentioned earlier, the bliss point $c_{2 i t}$ is exogenously determined, so $D E M_{i t-1}$ has no impact on $c_{2 i t}$. Therefore, if $D E M_{i t-1}$ is as good as randomly assigned, and has an effect on $D E M_{i t}$, then $D E M_{i t-1}$ would be a valid instrument for estimating $k_{0}$, the causal impact of $D E M_{i t}$ on $R C_{i t}$. On the other hand, under full or partial convergence, $m_{3}^{y} \neq 0$, and more likely $m_{3}^{y}>0$. So as $D E M_{i t-1}$ impacts $\delta_{i t}$, it will affect the equilibrium policy positions of both candidates, which would mean that $D E M_{i t-1}$ would not be a valid instrument for $D E M_{i t}$ in the above equation.

We have already argued that the first condition of the above proposition holds (see Proposition 1) if we restrict our attention to close elections in period $t-1$, and Lee $(2001,2002)$ provides strong evidence that the second condition holds (and we present some of that evidence in this paper). Using Proposition 1, it is easy to show that the RD-IV estimand (or the "local" Wald estimand, or the fuzzy regression discontinuity estimand $)^{15} \frac{E\left[R C_{i t} \mid V S_{i t-1}=\frac{1}{2}+\Delta\right]-E\left[R C_{i t} \mid V S_{i t-1}=\frac{1}{2}-\Delta\right]}{E\left[D E M_{i t} \mid V S_{i t-1}=\frac{1}{2}+\Delta\right]-E\left[D E M_{i t} \mid V S_{i t-1}=\frac{1}{2}-\Delta\right]}$ is approximately equal to

$$
\begin{aligned}
\approx & E\left[m^{y}\left(c_{1 i t}, c_{2 i t}, \delta_{i t}\right) \mid V S_{i t-1}=\frac{1}{2}+\Delta\right]-E\left[m^{y}\left(c_{1 i t}, c_{2 i t}, \delta_{i t}\right) \mid V S_{i t-1}=\frac{1}{2}-\Delta\right] \\
& +k_{0}
\end{aligned}
$$

Under complete divergence (and homogeneity), the first term is zero, so the RD-IV estimate equals $k_{0}$, which is also consistently estimated by the sharp regression discontinuity (RD) estimator in Equation 8. By contrast, if complete divergence does not hold, the first term is not zero, and hence the RD-IV estimator

\footnotetext{
15 For a recent formalization of the use of the regression discontinuity design to estimate causal effects, see Hahn, Todd, and van der Klaauw (2001).
} 
will not be consistent for $k_{0}$, and the RD-IV and RD estimates will differ.

Thus, our empirical test is based on assessing whether an exogenous change in the probability of a party winning the seat affects how the representative in that district votes after the next election. If the only effect is through impacting the relative odds of which party's position is implemented, the data are more consistent with full policy divergence. On the other hand, if there is an additional effect on the candidates' positions, the data would be more consistent with some degree of policy convergence.

In our empirical analysis, we show that condition 1) and 2) in the above proposition is strongly supported by the data. Therefore, a substantial difference between the RD and RD-IV estimates constitutes a rejection of the complete divergence hypothesis in favor of the alternative of partial convergence.

Test under Heterogeneity The basic intuition of our test holds under a more general model where $y_{i t}-x_{i t}$ is allowed to vary across districts, after some care is taken in the interpretation of the RD-IV estimand. In the discussion that follows, assume that we have conditioned on the districts involved in close elections in $t-1, \frac{1}{2}-\Delta<V S_{i t-1}<\frac{1}{2}+\Delta$, with $\Delta$ small. We denote $E_{\Delta}$ as the expectation conditional on these close elections in $t-1$. Note that among this group of districts, the average causal effect of $D E M_{i t-1}$ on $R C_{i t}$ (estimated by the numerator in $\frac{E\left[R C_{i t} \mid V S_{i t-1}=\frac{1}{2}+\Delta\right]-E\left[R C_{i t} \mid V S_{i t-1}=\frac{1}{2}-\Delta\right]}{E\left[D E M_{i t} \mid V S_{i t-1}=\frac{1}{2}+\Delta\right]-E\left[D E M_{i t} \mid V S_{i t-1}=\frac{1}{2}-\Delta\right]}$ ) is a weighted average of the causal effects for three sub-populations ${ }^{16}$ :

$$
\begin{gathered}
E_{\Delta}\left[x_{i t} \mid D E M_{i t-1}=1, S T R O N G_{t}^{D E M}\right]-E_{\Delta}\left[x_{i t} \mid D E M_{i t-1}=0, S T R O N G_{t}^{D E M}\right] \\
E_{\Delta}\left[y_{i t} \mid D E M_{i t-1}=1, S T R O N G_{t}^{R E P}\right]-E_{\Delta}\left[y_{i t} \mid D E M_{i t-1}=0, S T R O N G_{t}^{R E P}\right] \\
E_{\Delta}\left[x_{i t} \mid D E M_{i t-1}=1, S W I N G_{t}\right]-E_{\Delta}\left[y_{i t} \mid D E M_{i t-1}=0, S W I N G_{t}\right]
\end{gathered}
$$

The first expression represents the average effect of $D E M_{i t-1}$ on the Democrats' positions for the sub-population of Democrats $\left(S T R O N G_{t}^{D E M}\right)$ who would have won the election in period $t$ irrespective of $D E M_{i t-1}$. The second expression is the analogous effect for the sub-population of Republicans

\footnotetext{
16 This assumes a monotonicity condition - incumbency cannot have a negative impact on the probability of election. See Hahn, Todd, and van der Klauuw (2000), which discusses the regression discontinuity design analogy to the local average treatment effect (LATE) of Imbens and Angrist (1994).
} 
$\left(S T R O N G_{t}^{R E P}\right.$ ) who would have won election $t$ irrespective of $D E M_{i t-1}$. The final expression is the effect among the sub-population of districts $\left(S W I N G_{t}\right)$ that switched from Democratic to Republican control because of the incumbency advantage enjoyed by the Democrats in period $t-1\left(D E M_{t-1}\right)$. In the terminology of Angrist, Imbens, and Rubin (1996), the expressions represent the causal effects for the “always-takers", "never-takers" and "compliers", respectively.

There are two main implications of the complete divergence hypothesis - where positions are equal to pre-determined bliss points - when allowing for more general heterogeneity:

1. the first two effects should be zero; this is testable insofar the two effects can be estimated with data.

2. the third effect should be positive and equal to $E_{\Delta}\left[c_{1 i t}-c_{2 i t} \mid S W I N G_{t}\right]$. Strictly speaking, this is an untestable implication. The effect in Equation 14 can be estimated, but it will not be known whether it equals $E_{\Delta}\left[c_{1 i t}-c_{2 i t} \mid S W I N G_{t}\right]$ given that $c_{1 i t}$ and $c_{2 i t}$ are unobservable to the researcher. However, in a relatively stationary environment, a good approximation to $E_{\Delta}\left[c_{1 i t}-c_{2 i t} \mid S W I N G_{t}\right]$ would be $E_{\Delta}\left[c_{1 i t-1}-c_{2 i t-1} \mid S W I N G_{t}\right]$, which can be independently estimated. Under stationarity, a substantial departure between estimates of the two quantities constitutes a rejection of the full divergence hypothesis.

Normally, with one instrument and one endogenous regressor, it is impossible to identify the three sub-populations described above, and hence estimation of expressions 12, 13, and 14 is infeasible. However, in this particular context of elections, we can actually construct first-order approximations to these subpopulations in the data, because we observe the index $V S_{i t}$ which perfectly determines $D E M_{i t}$.

Proposition 4 Conditioning on the districts involved in close elections in $t-1, \frac{1}{2}-\Delta<V S_{i t-1}<$ $\frac{1}{2}+\Delta$, with $\Delta$ small, there exist $\theta_{1}$ and $\theta_{2}$ such that the three sub-populations can be, to the first-order, approximated as follows:

$$
\begin{aligned}
S T R O N G_{t}^{D E M} \text { if } D E M_{i t-1} & =0, D E M_{i t}=1 \\
\text { or } D E M_{i t-1} & =1, V S_{i t}>\frac{1}{2}+\theta_{1} \\
S T R O N G_{t}^{R E P} \text { if } D E M_{i t-1} & =1, D E M_{i t}=0 \\
\text { or } D E M_{i t-1} & =0, V S_{i t}<\frac{1}{2}-\theta_{2} \\
S W I N G_{t} \text { if } D E M_{i t-1}= & 0, \frac{1}{2}-\theta_{2}<V S_{i t}<\frac{1}{2} \\
\text { or } D E M_{i t-1} & =1, \frac{1}{2}<V S_{i t}<\frac{1}{2}+\theta_{1}
\end{aligned}
$$

where $\theta_{1}$ and $\theta_{2}$ are implicitly defined by $\operatorname{Pr}\left[V S_{i t}>\frac{1}{2}+\theta_{1} \mid D E M_{i t-1}=1\right]=\operatorname{Pr}\left[D E M_{i t}=1 \mid\right.$ $\left.D E M_{i t-1}=0\right]$ and $\operatorname{Pr}\left[V S_{i t}<\frac{1}{2}-\theta_{2} \mid D E M_{i t-1}=0\right]=\operatorname{Pr}\left[D E M_{i t}=0 \mid D E M_{i t-1}=1\right]$.

Thus, our testing procedure amounts to estimating the causal effects 12,13 , and 14 by dividing our 
sample of close elections in period $t-1$ into $S T R O N G_{t}^{D E M}, S T R O N G_{t}^{R E P}$, and $S W I N G_{t}$ groups, and estimating the mean difference in roll call votes $\left(R C_{i t}\right)$ between Democrat and Republican districts in period $t-1$ (by $D E M_{i t-1}$ ), for each group, respectively. If either 1) the first two effects substantially differ from zero, or 2) the third effect significantly departs from the benchmark $E_{\Delta}\left[x_{i t-1} \mid D E M_{i t-1}=1, S W I N G_{t}\right]$ $-E_{\Delta}\left[y_{i t-1} \mid D E M_{i t-1}=0, S W I N G_{t}\right] \approx E\left[c_{1 i t-1}-c_{2 i t-1} \mid S W I N G_{t}\right]$, we reject the complete divergence hypothesis in favor of the partial convergence equilibrium.

\section{Empirical Analysis}

\subsection{Data Description: Roll Call Voting Records in the U.S. House}

We begin by discussing the choice of the dependent variable. There are several alternative ways to measure politicians" "behavior" in voting on legislation. A widely used measure is a voting score created by the liberal political organization, Americans for Democratic Action (ADA). For each Congress, the ADA chooses about 20 high-profile roll call votes for the creation of an index that varies between 0 and 100 for each Representative of the House and member of the Senate. Higher scores correspond to a more "liberal" voting record. Throughout the paper, our preferred index of roll call votes is represented by ADA scores, although we show below that our results are robust to alternative interest groups scores and other voting record indices.

We utilize data on ADA scores for all Representatives in the U.S. House from 1946-1995, linked to election returns data during that period. ${ }^{17}$ There is considerable variation in ADA scores within each party. This is illustrated in Figure 1, which provides the distribution of ADA scores for Democrat and Republican U.S. House of Representatives in the three most recent Congresses. To make the comparison across congresses possible, we follow the literature and use "adjusted" ADA scores throughout the paper. ${ }^{18}$ The figure shows significant overlapping in ADA scores between the parties, and it is not uncommon for Democrat representatives to vote more conservatively than Republican candidates, and vice versa.

\footnotetext{
17 The data on roll call votes are from ICPSR 4. Data on electoral outcomes are from ICPSR 6311.

18 This adjustment to the nominal ADA score, was devised by Groseclose, Snyder and Levitt (1999). While nominal ADA scores are between 0 and 100, "adjusted" ADA scores may be negative.
} 
One advantage of using ADA scores is that it is a widely used index in the literature. However, one limitation is that it includes only 20 votes per legislature, and the choice of what roll call vote to include and what weight to assign to each issue is necessarily arbitrary. ${ }^{19}$ To assess how robust our results are to alternative measure of "liberalness" of roll call votes, have re-estimated all our models using four alternative sets of voting record measures.

First, we use the DW-NOMINATE scores constructed by McCarty, Poole and Rosenthal (1997). Poole and Rosenthal developed the NOMINATE procedure to estimate a low-dimensional measure of political ideology in a complex multidimensional political world. NOMINATE is an attempt to estimate the underlying ideology that drives observed roll call behavior by assigning legislators the ideological points that maximize the number of correctly predicted roll-call votes. Poole and Rosenthal noted that a single dimension would be unlikely to capture the division between Northern and Sourthern Democrats during the Civil Rights Era. Therefore, the NOMINATE procedure estimates a two-dimensional measure of ideology where the first dimension captures party loyalty and can be thought of as a liberal to conservative scale and the second dimension captures the issues of race that divided the Democrats until the mid-1970s. The NOMINATE procedure has the advantage of including all roll-call votes, not an arbitrary subset of votes. It also ignores the representative's political party and the legislative issue in question so it is arguably more exogeneous than the ADA Scores. To simplify the analysis, and to remain consistent with our discussion of a single ideological dimension, we restrict our analysis to the first dimension during the period where the second dimension had little predictive power. Specifically, we restrict our DW-NOMINATE analysis to 1975 and beyond. ${ }^{20}$

Second, for each member and each Congress, we construct our own measure of loyalty to the party leadership using the individual vote tallies on every issue voted on in the House. For this measure, we

\footnotetext{
19 Another disadvantage is that the choice of which vote to include is made at the end of the legislature, not at the beginning. (At the beginning of a legislature it is not obvious exactly which roll call will take place during a legislature.) This fact that the choice is made ex-post raises the possibility that the criteria used to assign ADA scores could be somewhat endogenous.

20 We use the DW-NOMINATE scores as opposed to the Poole and Rosenthal's earlier D-NOMINATE scores because the DW data covers up through the 106th Congress while the D-NOMINATE data ends with the 99th Congress. The choice of the DWNOMINATE data is unlikely to affect our results since McCarty, Poole, and Rosenthal note that the D-NOMINATE and DWNOMINATE scores are highly correlated where both scores are available. See Poole and Rosenthal (1997) for a description of the NOMINATE procedure. Poole's (1999) rank order data yields similar results.
} 
calculate the percent of a representative's votes that agree with the Democrat party leader. ${ }^{21}$

Third, we use ratings from interest groups other than the ADA. We include both liberal and conservative ratings from groups such as the American Civil Liberties Union, the League of Women Voters, the League of Conservation Voters, the American Federation of Government Employees, the American Federation of State, County, Municipal Employees, the American Federation of Teachers, the AFL-CIO Building and Construction, the United Auto Workers, the Conservative Coalition, the US Chamber of Commerce, the American Conservative Union, the Christian Voters Victory Fund, the Christian Voice, Lower Federal Spending, and Taxation with Representation. Not all the ratings are available in all years, so sample sizes vary when using these alternative ratings.

A legitimate concern is that the interest group may choose the criteria used to calculate their ratings based on partisan considerations. This could happen if partisan considerations enter interest groups decisions on which votes to include in the ratings, or the weight assigned to each vote. If this is the case, our finding could overstate the coefficient on party affiliation. Given that we use ratings from 15 different interest groups that are likely to use completely different criteria to create their ratings, we do not expect this to be a major problem.

However, we address this concern directly by creating our own ratings using roll call votes on abortion. We choose abortion because the classification of votes as pro-life or pro-choice is straightforward in most cases. For the three most recent Congresses for which we have data (102th to 104th), we identify all roll call votes that contain the word "abortion" in the title or the description, and assign each candidate a zero if the candidate voted pro-life and one if the candidate voted pro-choice. We then calculate the percentage of pro-choice votes for each candidate. Such an index is more objective than the interest group ratings, because it includes all votes on a specific issue, not just a selected sample, and assigns equal weight to all votes, not arbitrary weights.

As we show below, the qualitative results of our estimation are remarkably stable across alternative measures of roll call votes. This finding lends some credibility to the conclusion that our estimates are

$21 \quad$ The results are nearly identical if one uses the party whip instead of the party leader. 
not driven by the unique characteristics of one particular measure. See the Data Appendix for a detailed discussion of our samples and data sources.

\subsection{Graphical Analysis and Tests for Quasi-random Assignment}

In the remainder of this section we use the framework described in Section 3 to distinguish between full convergence, partial convergence and full divergence. We address the issues of unobserved parties' and legislators' preferences by using a regression discontinuity analysis based on close elections. We compare the roll call behavior of representatives from districts where the two-party vote share for the Democratic candidate is just below $50 \%$ with the roll call behavior of representatives from districts where the vote share for the Democratic candidate is just above $50 \%$.

We begin by empirically illustrating the discontinuity around the $50 \%$ threshold. We present two specification tests that lend some support to our assumption that close elections provide as-good-as randomized variation in party control of a seat. We then turn to the main results of the paper. First, we test for full convergence using ADA scores as a measure of roll call records. Having rejected full convergence - consistent with the findings of existing empirical studies - we then examine whether the data are more consistent with either complete divergence or partial convergence. We do this first under the assumption of homogeneity, and then under the more general assumption of heterogeneity. Finally, we show that our results do not change when we use alternative measures of roll call votes.

The top panel of Figure 2 plots ADA scores against the Democrat vote share. Data are for years 1946 to 1995 . Throughout the paper, the unit of observation is the district at a given point in time. But to give a general picture of the data, each point in Figure 2 is an average of the ADA score within 0.01-wide intervals of the vote share. The vertical line marks $50 \%$ of the two-party vote share. Districts to the right

of the vertical line are Democrat, districts to the left are Republican. The continuous line in Figure 2 is the predicted ADA scores from a regression that includes a 4th-order polynomial in vote share. A striking feature of the figure is that ADA scores appear to be a continuous and smooth function of vote shares everywhere, except at the threshold that determines party membership. There is a large discontinuous jump 
in ADA scores at the 50\% threshold, indicating that representatives from districts with similar vote shares have very different roll call behavior depending on the party to which they belong. ${ }^{22}$

Compare a district where the Democrat candidate barely lost (for example, vote share is $49 \%$ ), with a district where the Democrat candidate barely won, (for example, vote share is $51 \%$ ). As argued in Section 3, under the hypothesis of full convergence, we should observe little difference around the $50 \%$ threshold. On the contrary, it seems that representatives from districts with almost identical vote shares have widely different roll call records. The difference at the $50 \%$ threshold appears quite large. From the Figure it seems that representatives from districts on the Democrat side of the 50\% threshold have ADA scores that are almost 50 points higher than representatives from districts on the Republican side. A second striking feature of Figure 2 is the apparent lack of correlation between vote share and the ADA score. Democrats (Republicans) who barely won their districts subsequently have voting records that are just as liberal (conservative) as their fellow members who won their electoral races by landslides.

The key identifying assumption in our analysis is that as one compares closer and closer elections, all pre-determined characteristics of Republican and Democrat districts (including the district-specific bliss points) become more and more similar. We provide two pieces of evidence to support this assumption. First, in the bottom panel of Figure 2, we plot the ADA scores from the Congressional sessions that preceded the determination of the Democratic two-party vote share. If our identifying assumption is correct, we should observe no discontinuity in the relationship between lagged ADA scores (which are already determined before the assignment of the "treatment") and the vote share. If, on the contrary, the jump in the top panel is spurious, then we would expect to observe a jump in the lagged ADA scores. The lack of discontinuity lends some credibility to our identifying assumption. ${ }^{23}$

As a second specification check, we show that as we compare closer and closer elections, Republican and Democrat districts have other similar pre-determined characteristics. Consider, for example,

22 The discontinuity estimated by pooling all the years in Figure 2 masks some variation in the discontinuity gap across states and years. This is not surprising, as the political science literature, for example, has noted that in the South, Democrats and Republicans are ideologically closer than they are in the North. We have estimated the discontinuity by decade and by region. When we stratify by decade, we find that the estimated discontinuity is relatively smaller during the 1970s, and relatively larger during the 1990 s. When we stratify by region and decade, the discontinuity is relatively smaller in the South in the 1950s and 1970s.

23 The estimated gap is 3.5 (5.6). 
geographical location. There are sizable geographical differences in the full sample. Democrats are significantly more likely to be elected in the South than in the North and the West. However, as we start restricting the sample to closer and closer elections, the geographical differences decrease. For elections that are only within two percentage points from the threshold, the differences are not statistically significant.

This is shown in Figures 3 and 4, which plot district characteristics against vote share. Other than geographical location, we consider the following pre-determined characteristics: real income, percentage with high school degree, percentage black, percentage eligible to vote, and size of the voting population. ${ }^{24}$ Generally, the figures indicate that the magnitude of the discontinuity around the $50 \%$ threshold is small. ${ }^{25}$ Overall, we conclude that in a close neighborhood of 50\% Republican and Democrat districts have similar pre-determined characteristics, lending credibility to our main identifying assumption.

\subsection{Partial Convergence versus Full Divergence under Homogeneity}

The size of the discontinuity in ADA scores documented in Figure 2 is more precisely quantified in Table

1. All the entries in the table are based on close elections. Specifically, we include only districts with Democrat vote share at time $t-1$ between $48 \%$ and $52 \%: 48 \%<V S_{t-1}<52 \%$.

There are 915 such districts. We begin, in column 1, by reporting the coefficient on $D E M_{t}$ in a regression of $A D A_{t}$ on $D E M_{t}$, including only districts in which the vote share in the previous election is between $48 \%$ and $52 \%$. The estimated coefficient is 48.8 .

Column 2 reports an estimate of Equation 8. Specifically, it shows the RD estimate in a regression of $A D A_{t-1}$ on $D E M_{t-1}$. The mean difference in ADA scores at time $t-1$ between Democrat and Republican representatives that were elected in close elections is 47.6. This estimate corresponds to the magnitude of the discontinuity documented in the top panel of Figure 2. In the framework proposed in Section 3, such a large difference is a strong rejection of the full convergence hypothesis.

Having found evidence inconsistent with full convergence - the findings of other empirical studies

\footnotetext{
$24 \quad$ Data on districts characteristics in each election year are from the last available Census of Population. Because the census takes place every ten years, standard errors allow for clustering at the district-decade level.

25 One exception is the percentage blacks, for which the magnitude of the discontinuity is statistically significant. This is due to few outliers in the outer part of the vote share range. When the polynomial is estimated including only districts with vote share between $25 \%$ and $75 \%$, the coefficients becomes insignificant.
} 
- we turn to the question of whether the equilibrium can be best described as complete divergence or partial convergence. In Section 3, we illustrate that a way to distinguish between full divergence and partial divergence is to analyze the effect of an exogenous change in the probability of victory of a candidate. Under full divergence, we should observe little change in the candidates' policy positions. Under partial divergence, candidates should move toward their bliss points if facing an exogenously higher probability of winning. We empirically implement this test by using the party that wins the election at time $t-1$ as an instrument for the party that wins at time $t$, conditioning on close elections at time $t-1$. As shown in Proposition 3 above, under the null hypothesis of full divergence, RD-IV estimates are consistent and should be similar to the RD estimates shown in column 2 of Table 1 . Under the alternative hypothesis of partial divergence, RD-IV estimates are not consistent and are likely to exceed RD estimates in magnitude.

We begin by graphically showing the "first stage regresion" in the top panel of Figure 5, which plots $D E M_{t}$ against $V S_{t-1}$. The large discontinuity around the $50 \%$ threshold confirms that there exists a causal incumbency advantage, as documented in Lee $(2001,2002)$. For representatives who were elected in close elections at time $t-1$, such an incumbency advantage translates into an exogenous change in the probability of election at time $t$, which we use to distinguish between full divergence and partial divergence. The effect is quantified in column 3 of Table 1, which suggests that the first stage coefficient is 0.48 .

We now report the reduced-form estimates. In column 4, we show the coefficient on $D E M_{t-1}$ in a regression of $A D A_{t}$ on $D E M_{t-1}$. The estimated coefficient is 21.2 . The same effect is shown graphically in the bottom panel of Figure 5, which plots ADA scores at time $t-1$ against vote share in $t-1$.

Finally, we turn to the RD-IV estimator described in Section 3.2.2. The estimate in column 4 is 43.9, slightly smaller than the RD estimate in column 2. As the RD-IV and RD estimates are quite similar, we cannot reject the hypothesis of full divergence.

\subsection{Differentiating Between Convergence, Complete divergence and Partial Divergence Under Heterogeneity}

In the previous section, we tested the hypothesis of full divergence against the hypothesis of partial convergence under the assumption of homogeneity. We now turn to a more general framework where the 
difference between the parties' positions vary across districts and legislatures. Again, we focus on the 915 districts that experience close elections at time $t-1$.

We divide this group of districts in three sub-groups, based on the vote share at time $t$, according to the rules specified in Proposition 4. Strong Democrat districts include districts where a Republican (barely) won at time $t-1$ but a Democrat regained the district at time $t$. Strong Democrat districts also include the districts with the largest Democrat vote shares at time $t$, among the districts where a Democrat won at time $t-1 .^{26}$ There are 224 such districts. In the terminology of Angrist, Imbens and Rubin (1995) these districts are "always takers", because irrespective of the quasi-random assignment of $D E M_{t-1}$, they are Democrat at time $t$. Under complete divergence, we expect the ADA scores of representatives from strong Democrat districts at time $t$ to be unaffected by who wins the election at time $t-1$. Under partial convergence, a Democratic victory in $t-1$ should cause ADA scores to rise for this sub-population.

Similarly, strong Republican districts include those where a Democrat (barely) won at time $t-1$ but a Republican regained the district at time $t$, as well as districts with the largest Republican vote shares at time $t$, among the districts where a Republican won at time $t-1 .^{27}$ There are 250 such districts. These districts could be called "never takers" (Angrist, Imbens, Rubin (1995)), because irrespective of the "random assignment" of $D E M_{t-1}$, they are Republican at time $t$. Again, under complete divergence, we expect the ADA scores of representatives from strong Republican districts at time $t$ to be unaffected by who win the elections at time $t-1$. Under partial convergence, a Democratic victory in $t-1$ should cause ADA scores to rise for this sub-population.

Finally, we call the remaining districts swing districts. The swing districts are marginal districts that are neither safely Republican nor safely Democrat. They are districts who switched from Republican to Democratic control in $t$ because of a Democratic victory in $t-1$. For these districts, under complete divergence, the impact of a Democratic victory at time $t-1$ should on ADA scores should be similar to the

\footnotetext{
26 Specifically, we included the top $24.18 \%$ districts with the largest democrat vote share among the districts where a democrat won at time $t-1$. The reason why we included the top 24.18 districts is that among all the districts where the democrat lost at time $t-1$, the democrat candidate won at time $\mathrm{t}$ in $24.18 \%$ of the cases. Because there is "random assignment" at time $\mathrm{t}-1$, the probability of winning the elections at time $t$ for a democrat candidate irrespective of the outcome at time $t$ - 1 should be the same. ${ }_{27}$ Specifically, we included the $27.39 \%$ districts with the largest republican vote share, since among all the districts where the republican lost at time $t-1$, the republican candidate won at time $\mathrm{t}$ in $27.39 \%$ of the cases.
} 
average difference between the two parties' positions. There are 441 swing districts.

In the bottom part of Table 1 we report separate estimates for the three groups. Column 2 shows the coefficients from regressions of $A D A_{t-1}$ on $D E M_{t-1}$ for the three groups. The estimates are 52.1 for strong Democrat districts, 49.6 for swing districts and 44.4 for strong Republican districts. This suggests that the RD estimate of Equation 8 does not vary significantly across the three groups.

The key results are shown in column 4, where we regress $A D A_{t}$ on $D E M_{t-1}$. The coefficients for strong Democrat districts and strong Republican districts are not statistically different from zero. The coefficient for swing districts is the only one different from zero. Importantly, it is very similar to the RD coefficient in column 2. Based on the discussion in Section 3, these results strongly suggest the data are more consistent with full divergence.

\subsection{Sensitivity to Alternative Measures of Voting Records}

The empirical results are not specific to the ADA scores. We now show that the findings presented so far are similar when we use alternative measures of representatives' voting records.

Figure 6 is analogous to the top panel in Figure 2, but instead of using ADA scores, it is based on McCarty, Poole and Rosenthal's DW-NOMINATE scores (top panel) and the percent of votes cast that are equal to the vote cast by the Democrat party leader (bottom panel). The Figure indicates that, similar to the ADA scores, there is a large discontinuity at $50 \%$ of the vote share for both the DW-NOMINATE scores and the roll-call agreement with the Democrat party leader.

Tables 2 and 3 quantify the magnitude of the discontinuity and reports RD-IV estimates. All the qualitative results of Table 1 hold up using these measures. When we use the DW-NOMINATE scores, the RD estimate is 0.56 , remarkably close to the RD-IV estimate in column 5 , which is 0.58 . A pattern similar to the results for the ADA scores emerges in the bottom panel of Table 2, when the heterogeneous model is estimated. The effects of $R C_{t}$ on $D E M_{t-1}$ are virtually zero for strong Democrat and Republican districts, as would be predicted by full divergence. The reduced-form coefficient for the swing districts is 0.60 , remarkably similar to the $\mathrm{RD}$ estimate in column 2 . A similar story emerges from Table 3 , where we 
use the percent of votes cast that are in agreement with the Democrat party leader.

We now examine whether our results are robust when we use ratings from different interest groups. We have collected ratings from several liberal and conservative interest groups. Liberal groups include: American Civil Liberties Union, the League of Women Voters, the League of Conservation Voters, the American Federation of Government Employees, the American Federation of State, County, and Municipal Employees, the American Federation of Teachers, the AFL-CIO Building and Construction, the United Auto Workers. Conservative groups include: the Conservative Coalition, the U.S. Chamber of Commerce, the American Conservative Union, and the Christian Voice.

These alternative ratings yield results that are qualitatively similar to the results presented so far. Figures 7 to 10 show the relationship between ratings and the democrat vote share. All the ratings range from 0 to 100 . For liberal groups, low ratings correspond to conservative roll call votes, and high ratings correspond to liberal roll call votes. For conservative groups, the opposite is true. In all cases, we find a large discontinuity at $50 \%$ of the vote share. This finding is analogous to what we document in Figure 6 for nominate scores and probability of voting like the Democrat party leader. With all the measures we could find, we find a large discontinuity at the 50 percent threshold, but a generally flat relation between the voting score and the Democratic vote share elsewhere. Democrats (Republicans) who won elections by a large margin do not vote systematically different from Democrats (Republicans) who won by slim margins.

In Figure 11, we turn to the comparison of RD estimates and RD-IV estimates for each of these alternative interest group ratings. Instead of presenting these results in a table format as we did in Tables 1 to 3, we present the main results in a graphical form. The figure plots the RD estimates against the RD-IV estimates for each group. The diagonal is the $45^{\circ}$ degree line. Most estimates are on the line or close to the line, indicating again that across a variety of different interest groups scores, the results are highly consistent with the full divergence hypothesis.

Similar results are obtained from the ratings that we constructed based on roll call votes on abortion. Just to give an example, Figure 12 shows a pattern similar to the one uncovered for ADA scores in Figure 2. This provides evidence that the discontinuity documented in Figure 2 is not simply a consequence of 
partisan criteria used by ADA.

\section{Relation to Previous Empirical Studies}

Previous empirical studies have examined the extent to which party affiliation and constituents' preferences influence roll call voting behavior. ${ }^{28}$ Most studies conclude that political party affiliation is an important predictor of voting behavior. Poole and Rosenthal (1984), for example, show that senators from the same state belonging to different parties have significantly different voting records. More recently, Snyder and Groseclose (2000) estimate the effect of party affiliation on roll call votes using an innovative identification strategy based on lopsided votes. Their main concern is that the correlation between party affiliation and voting may be spurious, possibly reflecting legislators' or constituency preferences. Their strategy is based on the assumption that on votes with 65 percent or more legislators on one side, legislators are not subject to party influence. They conclude that in the majority of cases, party affiliation is a significant determinant of roll calls. ${ }^{29}$ In a study of Senatorial voting behavior Levitt (1996) also finds that political party is a key determinant of roll-call voting behavior, and that constituents' preferences are assigned a smaller weight in senator utility functions. ${ }^{30}$

The agreement between these findings and our quasi-experimental results on the issue of full convergence suggest that the previous literature's findings are not simply artifacts of selection bias. In particular, with the benefit of hindsight, our own analysis in Figures 2, 6, 7, 8, 9, 10 and 12 reveals that a simple difference in means would not have been a particularly biased estimate of the effect of party affiliation on roll call votes.

On the other hand, the existing literature does not directly address the main question that we focus on in this paper: whether roll call voting behavior in Congress is best described as a partial convergence or

\footnotetext{
28 An example of early empirical work in this area is Miller and Stokes (1963).

29 See Krehbiel (2000) and McCarty, Poole and Rosenthal (2000) for a different interpretation of the Snyder and Groseclose results.

30 The literature is too large to be summarized here. Other examples include, but are not limited to, Poole and Rosenthal (1996), Snyder and Ting (2001a), Fiorina (1999), Poole and Rosenthal (2001), Snyder and Ting (2001b), Lott and Davis (1992), CanesWrone, Brady and Cogan (2000), Krehbiel (2000), Bender (1991), Lott (1990), McArthur and Marks (1988), Douglas and Sielberger (1987), McCarty, Poole and Rosenthal (2000).
} 
complete policy divergence equilibrium. For example, in Levitt (1996), it is presumed that the Senator is making a trade-off between voters preferences and his own ideology, and the presumption that the marginal conditions are met for an "interior solution" is what justifies the fixed effects regression analysis. This is useful for estimating parameters of the implied utility function, but this approach is not informative about whether the equilibrium is an "interior" or "corner" solution in the first place. Indeed, in the dynamic framework of Alesina (1988), it is clear that the per-period first-order conditions are not met in the fully divergent equilibrium. ${ }^{31}$

\section{Conclusion}

Existing empirical studies on Congressional voting behavior typically show evidence strictly inconsistent with the complete policy convergence outcome. However, it would seem premature to reject the notion that electoral competition compels politicians to moderate their positions on the basis of rejecting the stark outcome of complete policy convergence. Indeed, the outcome of complete policy convergence may be too stark an equilibrium to be "realistic". Thus, an appropriate assessment of the ability of electoral competition to induce any degree of "compromise" rests on being able to empirically differentiate between partial policy convergence and complete policy divergence.

Within a fairly general theoretical framework, this paper empirically tests the bold prediction of the complete policy divergence hypothesis - that exogenous changes in the relative popularity of the candidates has no impact on the candidates' positions. We overcome the problem of not being able to directly measure the losing candidates' positions and as well as the parties' bliss points, which potentially vary across Congressional districts. We do so by exploiting the near-random assignment of party control of the seat that occurs among elections that turn out to be closely contested. Within the context of roll call voting behavior in the U.S. House, our RD estimates strongly reject the full policy convergence hypothesis, a finding consistent with the existing literature. More importantly, our RD-IV estimates provide no systematic evidence of partial convergence, and are strongly consistent with the sharp predictions of the complete divergence

31 When the first order conditions are met, Alesina's equation (6) holds, but the complete divergence equilibrium is in general different. 
equilibrium. Within the theoretical framework that we utilize, this finding is strictly inconsistent with the notion that politicians are able to make binding pre-commitments to policies (which generally leads to partial policy convergence).

It is important to realize that our results do not neccearily constitute a rejection of the overall "representativeness" of Congress. For example, one can define "representativeness" as the degree to which a politician represents the preferences of his/her core supporters. Our analysis would say nothing about this degree of representativeness. In loose terms, we have no way of knowing whether the Democratic (Republican) bliss point is exactly coincident with the most-preferred policy choice of the "median" Democratic (Republican) voter. It is possible that electoral competition in the U.S. primary system can work to force each party's nominee to represent the median voter within the party. Instead, our analysis takes the bliss points - representative or not - as given, and asks whether electoral competition compels politicians to deviate from those bliss points.

We also emphasize that since our analysis focuses on the voting behavior of representatives in the U.S. House, our findings may not generalize to other bodies of elected government, or to other measures of politician behavior (other than roll call voting behavior). In principle, the type of analysis presented here could be applied to contexts such as the U.S. Senate, or the state legislatures in the U.S., as well as the analysis of other dimensions of politician behavior. It may be true, for example, that electoral competition may have a greater influence on moderating the positions of opposing candidates in races for seats to state legislative assemblies. Although our analysis may not readily generalize to these other contexts, we nonetheless believe that if reputational mechanisms are able to sustain a certain degree of policy convergence, the U.S. House may be an ideal setting in which to observe this phenomenon. This is because the frequency of elections to the U.S. House, the absence of term-limits, the long tenures that we observe in the Congress, are all reasons why the force of reputational mechanisms should be relatively strong in the House. Furthermore, our analysis focuses on relatively "balanced" districts (closely contested elections), where it is (theoretically) easier to sustain convergent equilibria.

It is important to recognize that our interpretation of the findings depend on accepting the theoretical 
framework of Alesina (1988), which assumes, among other things, that voters are forward-looking and have rational expectations, that the two-party system is taken as given, that bliss points are exogenously pre-determined, that parties' objective functions are concave, and that all other things equal, a candidate can gain votes by moving his position closer to his/her opponent. Undoubtedly, making bliss points or the number of parties endogenous will make this issue more difficult to empirically examine, and may require different definitions of the notions of full and partial convergence, and full policy divergence. However, we maintain that until empirical analysis of an even more general framework is feasible, the framework of Alesina (1988) is useful for empirical analysis because 1) it has limited number of unobservable exogenous factors, 2) it makes a clear distinction between the full and partial convergence and full divergence, and most importantly, 3) it explicitly generates testable predictions that allow one to differentiate between the three types of equilibria.

Our empirical analysis suggests that there is little evidence that representatives in the U.S. House alter their positions (in either direction) in response to a large exogenous change in the probability of winning an election. While the degree of "reputation" and "ability to pre-commit" are not directly measurable, we believe that a leading explanation for our empirical findings is that the difficulty of establishing credible commitments to policies is an important real-world phenomenon. Thus, the assumption that politicians are unable to overcome this credibility problem, which has been adopted in more recent models of representative democracy (e.g. Besley and Coate 1997, 1998), appears to have some empirical support. 


\section{Appendix A.}

\section{Comparative Statics in the one-shot Nash Equilibrium (with binding pre-commitments)}

Consider $w^{1}$ and $w^{2}$ in a one-period game, where each party is able to make binding pre-commitments to policies, and chooses the optimal position given its (correct) expectation of its opponents' position. Let $P=F(\phi)$, where $\phi=\beta_{1} \delta-\beta_{2}(x+y)$, with $\beta_{1}, \beta_{2}>0$ (which captures the notion that an increase in $\delta$ leads to an increase in the probability that party 1 will win, and that, when $x>y$, movements toward more moderate positions will raise the probability of winning the election) and $F(\cdot)$ is a cdf corresponding to a probability density $f(\cdot)$. Let $\lambda(\cdot)=\frac{f(\cdot)}{F(\cdot)}$ and $\lambda^{*}(\cdot)=\frac{f(\cdot)}{1-F(\cdot)}$. We show below that if 1) $U(\cdot)$ and $V(\cdot)$ are concave (as assumed in the text), 2) $f(\cdot)$ is symmetric around (without loss of generality) 0,3$) \lambda^{\prime}(\cdot)<0$ for all real values (which would be the case if $f(\cdot)$ were a normal density, for example), 4) reaction functions are negatively sloped, and 5) we are considering an "interior" Nash equilibrium $\left(c_{2}<y<x<c_{1}\right)$, then the Nash equilibrium outcomes $x$ and $y$ both increase (move closer to party 1's bliss point) as $\delta$ increases: $\frac{d x}{d \delta}, \frac{d y}{d \delta}>0$

To see this, note that the Nash equilibrium is characterized by the two first-order conditions (with each equation implicitly defining a reaction function) $G^{1}(x, y, \delta)=-\beta_{2} \lambda(\phi)+\frac{U^{\prime}(x)}{U(x)-U(y)}=0$ and $G^{2}(x, y, \delta)=\beta_{2} \lambda^{*}(\phi)+\frac{V^{\prime}(y)}{V(y)-V(x)}=0$. Concavity of $U$ and $V$ and $\lambda^{\prime}(\cdot)<0$ (which implies, given symmetry of $\left.f(\cdot) \lambda^{* \prime}(\cdot)>0\right)$ implies that the second order conditions for a maximum hold: $G_{x}^{1}(x, y, \delta)$, $G_{y}^{2}(x, y, \delta)<0$

In order for reaction functions to be negatively sloped, it must be that $G_{y}^{1}(x, y, \delta), G_{x}^{2}(x, y, \delta)<0$. Negatively sloped reaction functions imply that the closer party 2's position is to party 1's position, party 1's optimal choice moves closer to party 2's position. The closer party 2's position is to its bliss point, the closer is party 1's optimal choice to party 1's bliss point. This is an intuitive assumption that captures the notion of the Downsian notion of electoral competition, except that parties care about the policy as well. In order for $G_{y}^{1}(x, y, \delta)$, we must have that $\beta_{2}^{2} \lambda^{\prime}(\phi)+\frac{d\left(\frac{U^{\prime}(x)}{U(x)-U(y)}\right)}{d y}<0$ (and similarly for $G_{x}^{2}(x, y, \delta)$ ) where the second term can be shown to be positive. Therefore, $\beta_{2}$ must be sufficiently high to make the reaction 
function negatively sloped. Note that if a party cares about the policy only if they win the election (and get a constant level of utility that does not vary with the policy if they lose), as long as $\beta_{2}$ is positive, reaction functions will be negatively sloped.

Given the structure of the first-order conditions, it can be shown that $\frac{G_{x}^{1}}{G_{y}^{1}}>1>\frac{G_{x}^{2}}{G_{y}^{2}}$ (which means that the Nash Equilibrium will be stable), which implies $G_{x}^{1} G_{y}^{2}-G_{x}^{2} G_{y}^{1}>0$. Thus, we only need to show that the numerators in each of the following expressions (which result from the implicit function theorem) are positive: $\frac{d x}{d \delta}=\frac{-G_{\delta}^{1} G_{y}^{2}+G_{\delta}^{2} G_{y}^{1}}{G_{x}^{1} G_{y}^{2}-G_{x}^{2} G_{y}^{1}}$ and $\frac{d y}{d \delta}=\frac{G_{\delta}^{1} G_{x}^{2}-G_{\delta}^{2} G_{x}^{1}}{G_{x}^{1} G_{y}^{2}-G_{x}^{2} G_{y}^{1}} \cdot \lambda^{\prime}(\cdot)<0$ implies that $G_{\delta}^{1}, G_{\delta}^{2}>0$. Therefore the numerator in $\frac{d x}{d \delta}=\frac{-G_{\delta}^{1} G_{y}^{2}+G_{\delta}^{2} G_{y}^{1}}{G_{x}^{1} G_{y}^{2}-G_{x}^{2} G_{y}^{1}}$ is positive if and only if $\frac{G_{y}^{1}}{G_{\delta}^{1}}>\frac{G_{y}^{2}}{G_{\delta}^{2}}$. After some manipulation, it can be shown that this will be true if and only if $\frac{\frac{d\left(\frac{U^{\prime}(x)}{U(x)-U(y)}\right)}{d y}}{-\beta_{1} \beta_{2} \lambda^{\prime}(\phi)}>\frac{\frac{d\left(\frac{V^{\prime}(y)}{V(y)-V(x)}\right)}{d y}}{\beta_{1} \beta_{2} \lambda^{* \prime}(\phi)}$. This inequality holds because the left-hand side is positive and the right side is negative (due to concavity of $V(\cdot)$ ). In the same way it can be shown that the numerator in $\frac{d y}{d \delta}=\frac{G_{\delta}^{1} G_{x}^{2}-G_{\delta}^{2} G_{x}^{1}}{G_{x}^{1} G_{y}^{2}-G_{x}^{2} G_{y}^{1}}$ is positive.

Thus, under these conditions, an exogenous increase in the relative popularity of party 1 (an increase in $\delta$ ) leads to both candidates moving towards party 1's bliss point.

Proof of Proposition 1 Denote the joint density of $V S_{i t}, c_{1 i t}, c_{2 i t}$, and $\delta_{i t}$ as $g\left(v s, c_{1}, c_{2}, \delta\right)$ and the density of $V S_{i t}$ as $h(v s) . g\left(v s, c_{1}, c_{2}, \delta\right)$ is continuous with respect to it arguments because $v s$ is a continuous function with respect to its arguments, and $c_{1 i t}, c_{2 i t}, \delta_{i t}$, and $\varepsilon_{i t}$ has continuous joint density by assumption. For the same reasons, $h$ is also continuous with respect to $v s$. Thus $\frac{g\left(v s, c_{1}, c_{2}, \delta\right)}{h(v s)}$ is continuous. See DiNardo and Lee (2002) and Lee (2002) to see how the result holds even if the heterogeneous components $\left(c_{1 i t}, c_{2 i t}, \delta_{i t}\right)$ have finite and discrete support, and only $\varepsilon_{i t}$ has continuous density.

Proof of Proposition 4 Condition on "close elections" in $t-1$. Consider the sub-population $D E M_{i t-1}=0, D E M_{i t}=1$. Clearly they belong to the group $S T R O N G^{D E M}$, by definition $\left(D E M_{i t-1}=\right.$ $0, D E M_{i t}=0$ do not). We need to show that, to a first-order approximation, for the population $D E M_{i t-1}=$ 1, Democrats would have won even if $D E M_{i t-1}=0$, if and only if $V S_{i t}>\frac{1}{2}+\theta_{1}$.

Consider the "vote production function", in equilibrium $V S_{i t}=v s\left(x\left(c_{1 i t}, c_{2 i t}, \delta_{i t}\right), y\left(c_{1 i t}, c_{2 i t}, \delta_{i t}\right)\right.$, $\left.\delta_{i t}, \varepsilon_{i t}\right)$. Taking a linear approximation to this function around the equilibrium yields (normalizing all co- 
efficients to 1) $V S_{i t} \approx-c_{1 i t}-c_{2 i t}+\delta_{i t}+\varepsilon_{i t}$. Furthermore, given Proposition 2, we can decompose $\delta_{i t}$ so that $V S_{i t} \approx-c_{1 i t}-c_{2 i t}+\gamma D E M_{i t-1}+\delta_{i t}^{*}+\varepsilon_{i t}$. Now, $\theta_{1}$ is defined so that $\operatorname{Pr}\left[-c_{1 i t}-c_{2 i t}+\delta_{i t}^{*}+\right.$ $\left.\varepsilon_{i t}>\frac{1}{2}\right]=\operatorname{Pr}\left[-c_{1 i t}-c_{2 i t}+\gamma+\delta_{i t}^{*}+\varepsilon_{i t}>\frac{1}{2}+\theta_{1}\right]$ which implies that $\theta_{1}=\gamma$. This implies that for $D E M_{i t-1}=1,-c_{1 i t}-c_{2 i t}+\delta_{i t}^{*}+\varepsilon_{i t}>\frac{1}{2}$ if and only if $V S_{i t}>\frac{1}{2}+\theta_{1}$.

A similar argument holds for the $S T R O N G^{R E P}$ and $S W I N G$ districts. 


\section{Appendix B.}

\section{Data Appendix}

The election data used in our analysis comes from ICPSR Study 6311 "Elections to the United States House of Representatives, 1898-1992," compiled by Gary King. ICPSR 6311 reports the state, district, incumbency status, and the total votes received by the Republican and Democrat candidates. ICPSR 6311 has the advantage that King distinguishes between "normal" elections that can be characterized as a Republican running against a Democrat, with no important independent candidates, and all other elections labeled as "exceptions." We drop the 304 "exceptions" between 1946 and 1992 leaving 10,138 observations - roughly 422 observations per congressional session from 1946 to 1992 . The 1994 election data was obtained from the U.S. House of Representatives' Office of the Clerk's website.

The "abortion" voting score outlined in Section 4.1 and the percentage of votes that agreed with the Democratic leader were obtained from ICPSR Study 4 "United States Congressional Roll Call Voting Records." After creating these scores as described in the text, we merged ICPSR 4 by state, district and congressional session onto 6311. A small random sample was drawn after the merge and checked against published sources to verify that the merge had worked correctly.

The Americans for Democratic Action interest group ratings were taken from Timothy J. Groseclose's website. As mentioned in the text, we use "adjusted" ADA scores to be able to compare ratings across sessions of congress. See Groseclose, Levitt, and Snyder (1999) for a description of the procedure used to calculate the "adjusted" ADA scores. We replicated the analysis in the paper with the "nominal" ADA scores and found no qualitative difference in our findings.

Congressional District Data for 1962-1970 was taken from ICPSR Study 10 "United States Congressional District Data Books.” Congressional District Data for 1972-1980 was taken from ICPSR Study 11 "United States Congressional District Data Book for the Ninety-Third Congress." Congressional District Data for 1982-1990 was taken from ICPSR Study 8710 “Census of Population and Housing, 1980 [United States]: STF3D Congressional District-level Extract." Congressional District Data for 1992 was taken from 
the 1990 Congressional District level extract. All districts during a given decade were assigned the most recent census value. For example, 1974 congressional districts were assigned the 1970 census values.

Keith T. Poole's website provided much of the data used in this paper. The non-ADA interest group ratings came from Poole and Daniels' (1985) interest group rating data which contains 59 interest group ratings scores, each covering some or all of the years between 1959 and 1981. McCarty, Poole and Rosenthal's DW-NOMINATE scores and Poole's rank ordering data were also found at Poole's website. For a description of the NOMINATE procedure see Poole and Rosenthal (1997), and for a specific description of the DW-NOMINATE scores see McCarty, Poole and Rosenthal (1997) and for a description of the rank order procedure see Poole (1999).

James Snyder was kind enough to provide us with the Presidential Election returns by Congressional District from 1952 to 1996 for a previous draft of this paper. 


\section{References}

[1] Aldrich, John H. (1983). "A Downsian Spatial Model with Party Activism” American Political Science Review, 77(4): 974-990.

[2] Alesina, Alberto (1988). "Credibility and Policy Convergence in a Two-Party System with Rational Voters", American Economic Review, 78, 796-805.

[3] Alesina, Alberto and Spear, Stephen E. (1988). "An Overlapping Generations Model of Electoral Competition”, Journal of Public Economics, 37, 359-379.

[4] Angrist, J., Imbens, G., and Rubin, D. (1996) "Identification of Causal Effects Using Instrumental Variables," Journal of the American Statistical Association, 91, 444-445.

[5] Baron, David P. "Electoral Competition with Informed and Uninformed Voters," American Political Science Review 88(1): 33-47.

[6] Besley, Timothy, and Stephen Coate (1997). "An Economic Model of Representative Democracy", Quarterly Journal of Economics, 112, 85-114.

[7] Besley, Timothy, and Stephen Coate (1998). "Sources of Inefficiency in a Representative Democracy: A Dynamic Analysis", American Economic Review, 88, 139-156.

[8] Bullock and Brady "Party Constituency, and Roll-Call Voting in the US Senate" Legislative Studies Quarterly 8 (1983).

[9] Calvert, Randall L. (1985). "Robustness of the Multidimensional Voting Model: Candidate Motivations, Uncertainty, and Convergence." American Journal of Political Science, 29, 69-95.

[10] Canes-Wrone, Brady and Cogan "Electoral Accountability and House Members' Voting" mimeo (2001).

[11] Coleman, J.S. (1971). "Internal Processes Governing Party Positions in Elections" Public Choice. 11:34-60.

[12] DiNardo, John, and David S. Lee (2002). "The Impact of Unionization on Establishment Closure: A Regression Discontinuity Analysis of Representation Elections," NBER Working Paper \#8993, June 2002.

[13] Downs, Anthony (1957). An Economic Theory of Democracy, New York, NY: Harper and Row.

[14] Fiorina, Morris P. (1999) "What Ever Happened to the Median Voter?" Annual Meetings of the Midwest Political Science Association, Chicago.

[15] Groseclose, Timothy J. ADA SCORES, 1947-1999 [Computer File]. http://faculty-gsb.stanford.edu/ groseclose/archive.htm (12 February 2002).

[16] Grossman, Gene M., and Elhanan Helpman. "Electoral Competition and Special Interest Politics" Review of Economic Studies 63(2): 265-286.

[17] Hahn, Jinyong, Petra Todd, and Wilbert van der Klaauw (2001). "Identification and Estimation of Treatment Effects with a Regression-Discontinuity Design", Econometrica 69, 201-209.

[18] Heckman and Snyder "A Linear latent Factor Voting Model”, Rand Journal of Economics 28-0 (1997).

[19] Hinich, Melvin, Ledyard, John and Ordeshook, Peter (1972). "Nonvoting and the Existence of Equilibrium Under Majority Rule," Journal of Economic Theory, 4, 144-53.

[20] Imbens, G., and Angrist, J. (1994). "Identification and Estimation of Local Average Treatment Effects", Econometrica, 62 (4): 467-476.

[21] Inter-university Consortium for Political and Social Research and Carroll McKibbin. ROSTER OF UNITED STATES CONGRESSIONAL OFFICEHOLDERS AND BIOGRAPHICAL CHARACTERISTICS OF MEMBERS OF THE UNITED STATES CONGRESS, 1789-1996: MERGED DATA [Computer file]. 10th ICPSR ed. Ann Arbor, MI: Inter-university Consortium for Political and Social Research [producer and distributor], 1997.

[22] Inter-university Consortium for Political and Social Research. UNITED STATES CONGRESSIONAL 
ROLL CALL VOTING RECORDS, 1789-1990 [Parts 1-202] [Computer file]. ICPSR ed. Ann Arbor, MI: Inter-university Consortium for Political and Social Research [producer and distributor], 2001.

[23] Inter-university Consortium for Political and Social Research and Congressional Quarterly, Inc. UNITED STATES CONGRESSIONAL ROLL CALL VOTING RECORDS, 1789-1994 [Parts 203-206] [Computer file]. ICPSR ed. Ann Arbor, MI: Inter-university Consortium for Political and Social Research/ Washington, DC: Congressional Quarterly, Inc. [producers], 1997. Ann Arbor, MI: Inter-university Consortium for Political and Social Research [distributor], 1997.

[24] Inter-university Consortium for Political and Social Research and Congressional Quarterly, Inc. UNITED STATES CONGRESSIONAL ROLL CALL VOTING RECORDS, 1789-1996 [Parts 207-208] [Computer file]. ICPSR ed. Ann Arbor, MI: Inter-university Consortium for Political and Social Research/ Washington, DC: Congressional Quarterly, Inc. [producers], 1998. Ann Arbor, MI: Inter-university Consortium for Political and Social Research [distributor], 1998.

[25] Kalt and Zupan "Capture and Ideology in the Economic Theory of Politics" American Economic Review 74-3 (1984).

[26] Kalt and Zupman "The Apparent Ideological Behavior of Legislators: Testing Principal-Agent Slack in Political Institutions" Journal of Law and Economics 33-1 (1990).

[27] Kau and Rubin "Self-Interest, Ideology and Log-rolling in Congressional Voting" Journal of Law and Economics 22-2 (1979).

[28] King, Gary. ELECTIONS TO THE UNITED STATES HOUSE OF REPRESENTATIVES, 1898-1992 [Computer file]. ICPSR version. Cambridge, MA: Gary King [producer], 1994. Ann Arbor, MI: Interuniversity Consortium for Political and Social Research [distributor], 1995.

[29] Krehbiel, Keith (2000). "The Coefficient of Party Influence", Stanford Graduate School of Business Research Paper No. 1646.

[30] Lee, David S. (2001) “The Electoral Advantage to Incumbency and Voters' Valuation of Politicians' Experience: A Regression Discontinuity Analysis of Close Elections”, UC Berkeley Center for Labor Economics, Working Paper \#31, April 2001.

[31] Lee, David S. (2002)."Regression Discontinuity Analysis of the Incumbency Advantage in the U.S. House", UC Berkeley Manuscript, June 2002.

[32] Levitt "How Do Senators Vote? Disentangling the Role of Voter Preferences, Party Affiliation, and Senator Ideology" American Economic Review, 86-3 (1996).

[33] Levitt, Steven D., Groseclose, Tim and James M. Snyder Jr. "Comparing Interest Group Scores across Time and Chambers: Adjusted ADA Scores for the U.S. Congress." American Political Science Review 93, no.1 (March 1999): 33-50.

[34] McCarty, Nolan M., Poole, Keith T., Rosenthal, Howard. Income Redistribution and the Realignment of American Politics. Washington, D.C.: The AEI Press, 1997.

[35] McCarty, Nolan, Poole, Keith, Rosenthal, Howard (2000). "The Hunt for Party Discipline in Congress", American Political Science Review, 95, 3, 673-687.

[36] McKelvey, Richard (1975). "Policy Related Voting and Electoral Equilibrium," Econometrica, 43, 815-63.

[37] Miller, Warren E., Stokes, Donald E. (1963). “Constituency Influence in Congress”, American Political Science Review, 57, 1, 45-56.

[38] Osborne, Martin J. (1995). "Spatial models of Political Competition under Plurality Rule: A survey of Some Explanations of the Number of Candidates and the Position they Take", Canadian Journal of Economics, 28, 261-301.

[39] Peltzman "An Economic Interpretation of the History of Congressional Voting in the Twentieth Century" American Economic Review 75-4 (1985).

[40] Persson, Torsten, and Guido Tabellini (2000). Political Economics. Cambridge, MA: MIT Press. 
[41] Poole, Keith T. "Changing Minds? Not in Congress!" GSIA WP \#1997-22, forthcoming in Changing Minds, ed. by Michael Munger and Bryan Roberts. New York: Cambridge University Press, 1999.

[42] Poole, Keith T. DW-NOMINATE SCORES FOR HOUSE, 1st-106th SESSION OF CONGRESS [Computer File]. http://voteview.uh.edu/default_nomdata.htm (25 September 2002).

[43] Poole, Keith T. INTEREST GROUP RATINGS, 1959-1981 [Computer File]. http://voteview.uh.edu/ dwnominate.htm (12 February 2002).

[44] Poole, Keith T. RANK ORDER FOR THE HOUSE, 1947-1996 [Computer File]. http:// voteview.uh.edu/ default_nomdata.htm (25 September 2002).

[45] Poole and Daniels "Ideology, Party and Voting in the US Congress 1959-1980" American Political Science Review 79-2 (1985).

[46] Poole and Rosenthal "The Polarization of American Politics" Journal of Politics 46-4 (1984).

[47] Poole and Rosenthal "A Spatial Model for Roll Call Analysis" American Journal of Political Science 29- 2 (1985).

[48] Poole and Rosenthal "Patterns of Congressional Voting" American Journal of Political Science 35-1 (1991).

[49] Poole and Rosenthal (2001) "D-Nominate after 10 years" Legislative Studies Quarterly 26 5-30.

[50] Snyder “Artificial Extremism in Interest Group Ratings" Legislative Studies Quarterly 17-3 (1992).

[51] J. Snyder and T. Grosecolse "Estimating Party Influence in Congressional Roll- Call Voting" American Journal of Political Science, 44-2, pp.187-205 (2000).

[52] J. Snyder and M. Ting "Party Labels, Roll-Call Votes, and Elections" mimeo (2001a).

[53] J. Snyder and M. Ting “An Information Rational for Political parties" mimeo (2001b).

[54] U.S. Dept. of Commerce, Bureau of the Census. CENSUS OF POPULATION AND HOUSING, 1980 [UNITED STATES]: SUMMARY TAPE FILE 3D CONGRESSIONAL DISTRICT-LEVEL EXTRACT [Computer file]. Milwaukee, WI: John McAdams, Marquette University [producer], 198 ?. Ann Arbor, MI: Inter-university Consortium for Political and Social Research [distributor], 1987.

[55] U.S. Dept. of Commerce, Bureau of the Census. CENSUS OF POPULATION AND HOUSING, 1990 [UNITED STATES]: SUMMARY TAPE FILE 3D CONGRESSIONAL DISTRICTS OF THE UNITED STATES, 103RD CONGRESS [Computer File]. Washington, D.C.: U.S. Dept. of Commerce, Bureau of the Census, 1993.

[56] U.S. Dept. of Commerce, Bureau of the Census. UNITED STATES CONGRESSIONAL DISTRICT DATA BOOKS, 1961-1965 [Computer file]. ICPSR ed. Ann Arbor, MI: Inter-university Consortium for Political and Social Research [producer and distributor], 196 ?.

[57] U.S. Dept. of Commerce, Bureau of the Census. UNITED STATES CONGRESSIONAL DISTRICT DATA BOOK FOR THE NINETY-THIRD CONGRESS, 1973 [Computer file]. ICPSR ed. Ann Arbor, MI: Inter-university Consortium for Political and Social Research [producer and distributor], 1999.

[58] Wittman, Donald (1977). “Candidates with Policy Preferences: A Dynamic Model” Journal of Economic Theory, 14(1): 180-89.

[59] Wittman, Donald (1983). "Candidate Motivation: A synthesis of Alternative Theories", American Political Science Review, 77, 142-157. 
Table 1: Estimates based on ADA Scores, Conditioning on Close Elections at Time $t-1$

\begin{tabular}{|c|c|c|c|c|c|c|}
\hline & $\begin{array}{c}A D A_{t} \\
(1)\end{array}$ & $\begin{array}{c}\mathrm{RD} \\
A D A_{t-1} \\
(2) \\
\end{array}$ & $\begin{array}{c}\text { First Stage } \\
D E M_{t} \\
(3) \\
\end{array}$ & $\begin{array}{c}\text { Reduced Form } \\
A D A_{t} \\
(4) \\
\end{array}$ & $\begin{array}{c}\mathrm{RD}-\mathrm{IV} \\
A D A_{t} \\
(5) \\
\end{array}$ & $\begin{array}{l}\mathrm{N} \\
(6) \\
\end{array}$ \\
\hline \multicolumn{7}{|l|}{ Homogeneity } \\
\hline$\overline{\text { Coefficient on }} D E M_{t}$ & $\begin{array}{l}48.8 \\
(1.3)\end{array}$ & & & & $\begin{array}{l}43.9 \\
(2.7)\end{array}$ & 915 \\
\hline Coefficient on $D E M_{t-1}$ & & $\begin{array}{l}47.6 \\
(1.3)\end{array}$ & $\begin{array}{c}0.48 \\
(0.02)\end{array}$ & $\begin{array}{l}21.2 \\
(1.9)\end{array}$ & & 915 \\
\hline \multicolumn{7}{|l|}{ Heterogeneity } \\
\hline \multicolumn{7}{|c|}{$\overline{\text { Strong Democrat Districts }}$} \\
\hline Coefficient on $D E M_{t-1}$ & & $\begin{array}{l}52.1 \\
(3.1)\end{array}$ & & $\begin{array}{l}-1.7 \\
(3.0)\end{array}$ & & 224 \\
\hline \multicolumn{7}{|l|}{ Swing Districts } \\
\hline$\overline{\text { Coefficient on } D} E M_{t-1}$ & & $\begin{array}{l}49.6 \\
(1.8)\end{array}$ & & $\begin{array}{l}47.4 \\
(1.8)\end{array}$ & & 441 \\
\hline \multicolumn{7}{|c|}{ Strong Republican Districts } \\
\hline$\overline{\text { Coefficient on } D E M_{t-1}}$ & & $\begin{array}{l}44.4 \\
(2.5)\end{array}$ & & $\begin{array}{l}-4.6 \\
(2.3)\end{array}$ & & 250 \\
\hline
\end{tabular}

Notes: Standard errors in parenthesis. $A D A_{t}$ is the adjusted ADA voting score. Only observations for which the democrat vote share at time $t-1$ is between $48 \%$ and $52 \%$ are included. Time $t$ and $t-1$ refer to congressional sessions. See text for details. 
Table 2: Estimates based on Nominate Scores, Conditioning on Close Elections at Time t-1

\begin{tabular}{|c|c|c|c|c|c|c|}
\hline & $\begin{array}{l}N_{t} \\
(1)\end{array}$ & $\begin{array}{c}\mathrm{RD} \\
N_{t-1} \\
(2)\end{array}$ & $\begin{array}{c}\text { First Stage } \\
D E M_{t} \\
(3)\end{array}$ & $\begin{array}{c}\text { Reduced Form } \\
N_{t} \\
(4)\end{array}$ & $\begin{array}{c}\text { RD-IV } \\
N_{t} \\
(5)\end{array}$ & $\begin{array}{l}\mathrm{N} \\
(6)\end{array}$ \\
\hline \multicolumn{7}{|l|}{ Homogeneity } \\
\hline$\overline{\text { Coefficient on }} D E M_{t}$ & $\begin{array}{l}-0.58 \\
(0.02)\end{array}$ & & & & $\begin{array}{l}-0.58 \\
(0.04)\end{array}$ & 276 \\
\hline Coefficient on $D E M_{t-1}$ & & $\begin{array}{c}-0.56 \\
(0.02)\end{array}$ & $\begin{array}{c}0.62 \\
(0.02)\end{array}$ & $\begin{array}{c}-0.36 \\
(0.03)\end{array}$ & & 276 \\
\hline \multicolumn{7}{|l|}{ Heterogeneity } \\
\hline \multicolumn{7}{|l|}{ Strong Democrat Districts } \\
\hline Coefficient on $D E M_{t-1}$ & & $\begin{array}{c}-0.55 \\
(0.08)\end{array}$ & & $\begin{array}{c}-0.01 \\
(0.08)\end{array}$ & & 36 \\
\hline \multicolumn{7}{|l|}{ Swing Districts } \\
\hline$\overline{\text { Coefficient on } D} E M_{t-1}$ & & $\begin{array}{l}-0.59 \\
(0.03)\end{array}$ & & $\begin{array}{l}-0.60 \\
(0.03)\end{array}$ & & 172 \\
\hline \multicolumn{7}{|l|}{ Strong Republican Districts } \\
\hline Coefficient on $D E M_{t-1}$ & & $\begin{array}{l}-0.49 \\
(0.04)\end{array}$ & & $\begin{array}{l}-0.03 \\
(0.05)\end{array}$ & & 68 \\
\hline
\end{tabular}

Notes: Standard errors in parenthesis. $N_{t}$ is the DW-NOMINATE score constructed by McCarty, Poole and Rosenthal. Only observations for which the democrat vote share at time $t-1$ is between $48 \%$ and $52 \%$ are included. Time t and t-1 refer to congressional sessions. See text for details. 
Table 3: Estimates based on the Probability of Voting like the Democrat Leader, Conditioning on Close Elections at Time t-1

\begin{tabular}{|c|c|c|c|c|c|c|}
\hline & $\begin{array}{l}P_{t} \\
(1)\end{array}$ & $\begin{array}{c}\mathrm{RD} \\
P_{t-1} \\
(2) \\
\end{array}$ & $\begin{array}{c}\text { First Stage } \\
D E M_{t} \\
(3)\end{array}$ & $\begin{array}{c}\text { Reduced Form } \\
P_{t} \\
(4) \\
\end{array}$ & $\begin{array}{c}\text { RD-IV } \\
P_{t} \\
(5) \\
\end{array}$ & $\begin{array}{l}\mathrm{N} \\
(6) \\
\end{array}$ \\
\hline \multicolumn{7}{|l|}{ Homogeneity } \\
\hline$\overline{\text { Coefficient on }} D E M_{t}$ & $\begin{array}{c}0.302 \\
(0.007)\end{array}$ & & & & $\begin{array}{c}0.294 \\
(0.015)\end{array}$ & 1010 \\
\hline Coefficient on $D E M_{t-1}$ & & $\begin{array}{c}0.291 \\
(0.006)\end{array}$ & $\begin{array}{c}0.46 \\
(0.02)\end{array}$ & $\begin{array}{c}0.138 \\
(0.011)\end{array}$ & & 1010 \\
\hline \multicolumn{7}{|l|}{ Heterogeneity } \\
\hline \multicolumn{7}{|l|}{ Strong Democrat Districts } \\
\hline Coefficient on $D E M_{t-1}$ & & $\begin{array}{c}0.290 \\
(0.016)\end{array}$ & & $\begin{array}{c}0.001 \\
(0.011)\end{array}$ & & 248 \\
\hline \multicolumn{7}{|l|}{ Swing Districts } \\
\hline$\overline{\text { Coefficient on } D} E M_{t-1}$ & & $\begin{array}{c}0.290 \\
(0.009)\end{array}$ & & $\begin{array}{c}0.308 \\
(0.010)\end{array}$ & & 474 \\
\hline \multicolumn{7}{|l|}{ Strong Republican Districts } \\
\hline Coefficient on $D E M_{t-1}$ & & $\begin{array}{c}0.294 \\
(0.012)\end{array}$ & & $\begin{array}{c}0.024 \\
(0.016)\end{array}$ & & 288 \\
\hline
\end{tabular}

Notes: Standard errors in parenthesis. $P_{t}$ is the percent of a representative's votes that agree with the Democrat party leader. Only observations for which the democrat vote share at time $t-1$ is between $48 \%$ and $52 \%$ are included. Time t and t- 1 refer to congressional sessions. See text for details. 
Figure 1: Distribution of ADA Scores, by Party
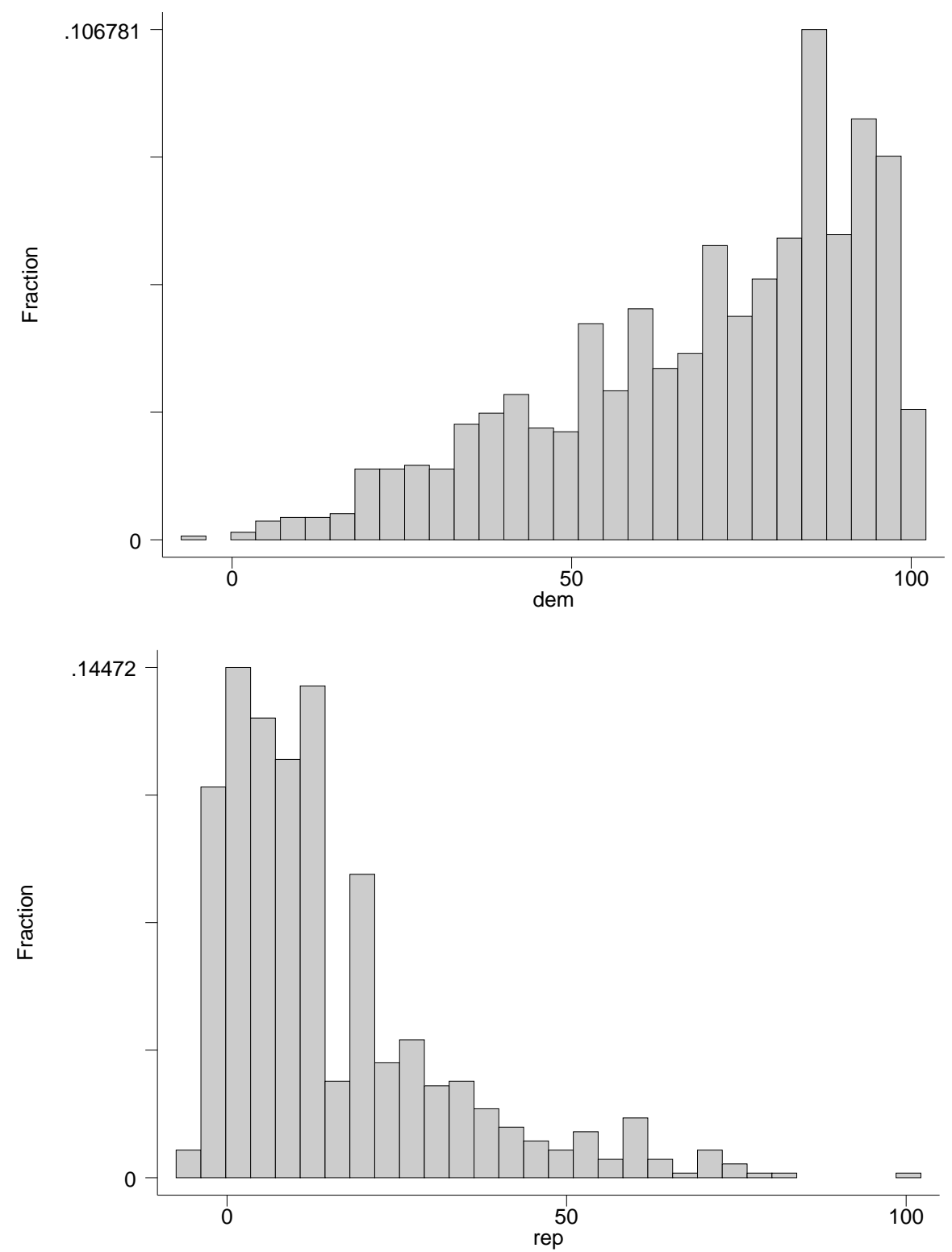

Notes: The top panel shows the distribution of adjusted ADA scores for Democrats in Congresses 102, 103 and 104. The bottom panel shows the distribution of adjusted ADA scores for Republicans in the same period. 
Figure 2: ADA Scores and Lagged ADA Scores, by Democrat Vote Share

\section{Contemporaneous ADA Scores}

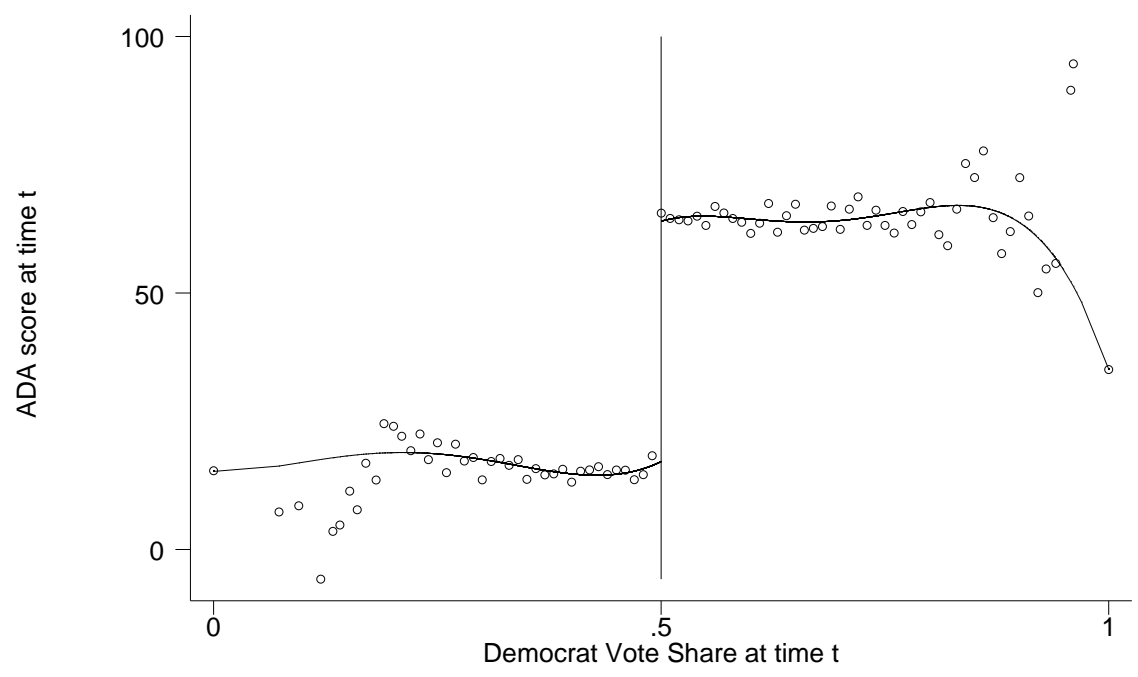

Lagged ADA Scores

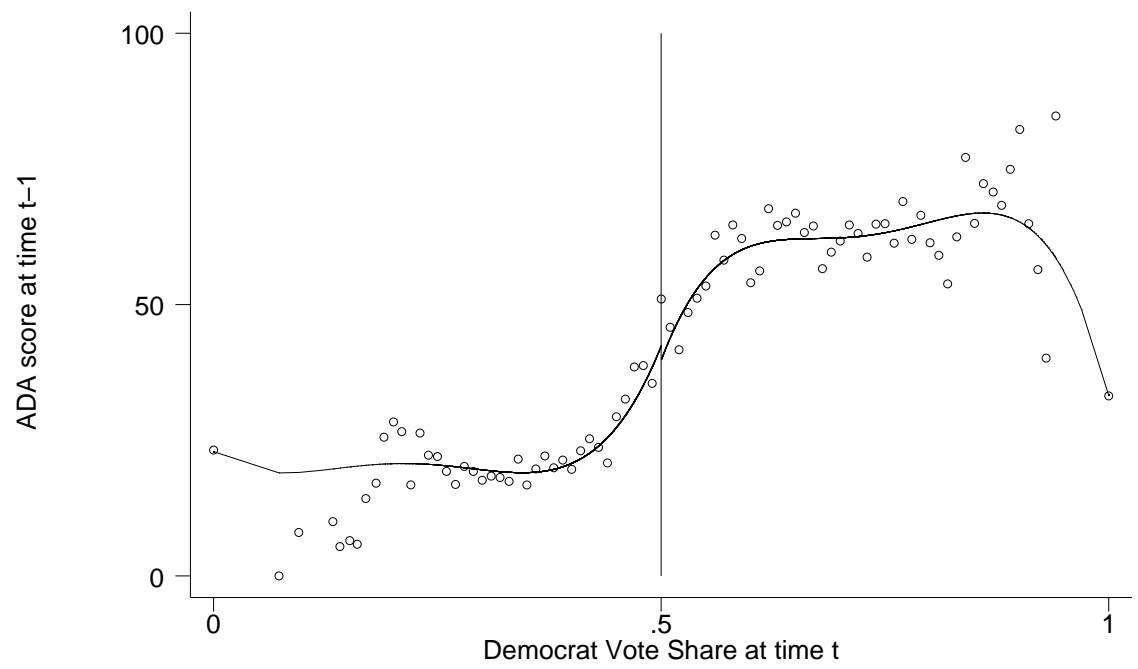

Notes: The top panel plots ADA scores against the democrat vote share. Each point is the average ADA score within intervals 0.01 wide. The bottom panel plots one time lagged ADA scores against the democrat vote share. Time $t$ and $t-1$ refer to congressional sessions. Each point is the average lagged ADA score within intervals 0.01 wide. 
Figure 3: Are Constituents' Characteristics Different in Democrat and Republican Districts? Part 1
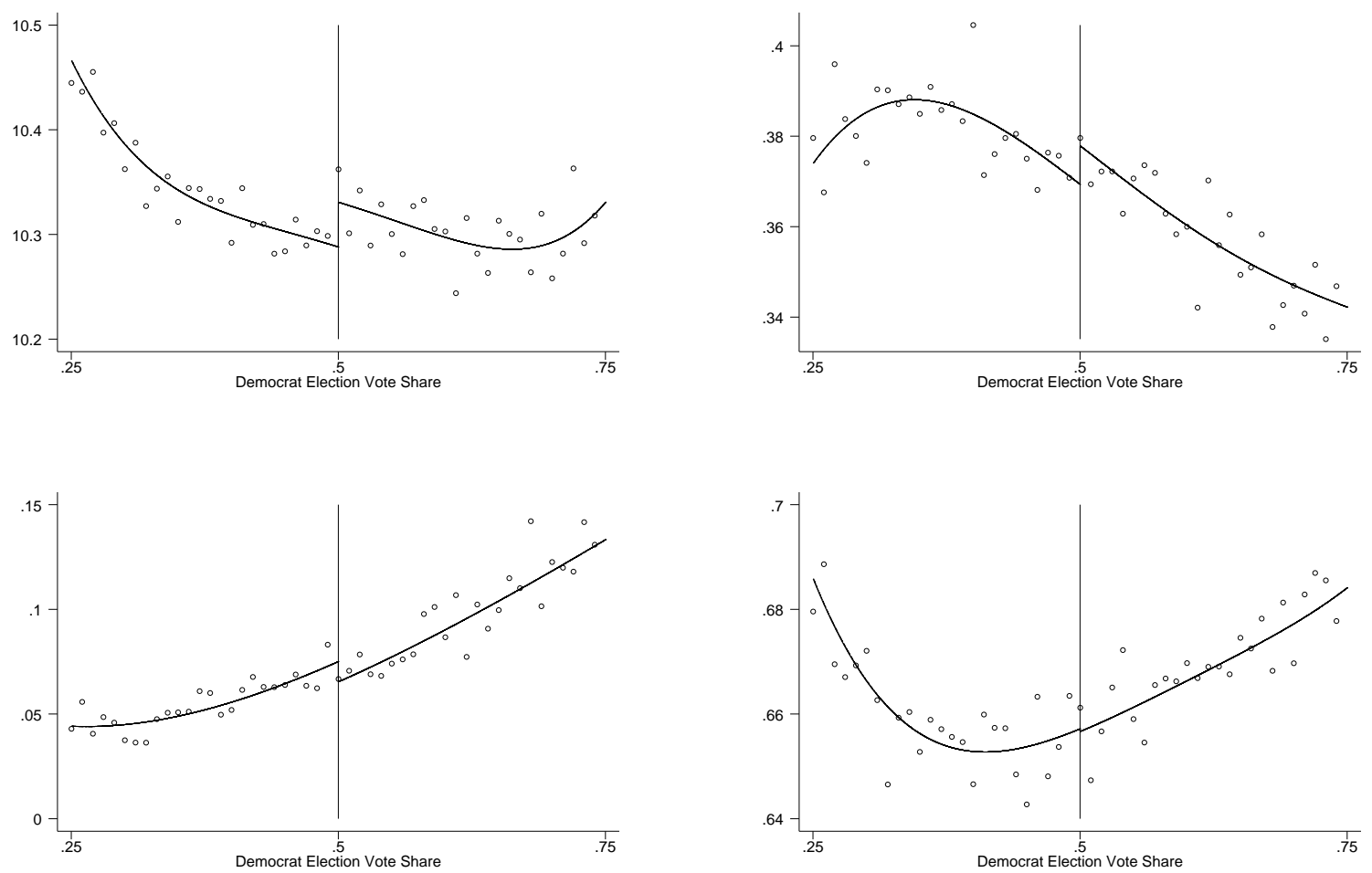

Notes: Panels refer to (from top left to bottom right) the following district characteristics: real income, percentage with high-school degree, percentage black, percentage eligible to vote. Each point is the average characteristic within intervals 0.01 wide. 
Figure 4: Are Constituents' Characteristics Different in Democrat and Republican Districts? Part 2
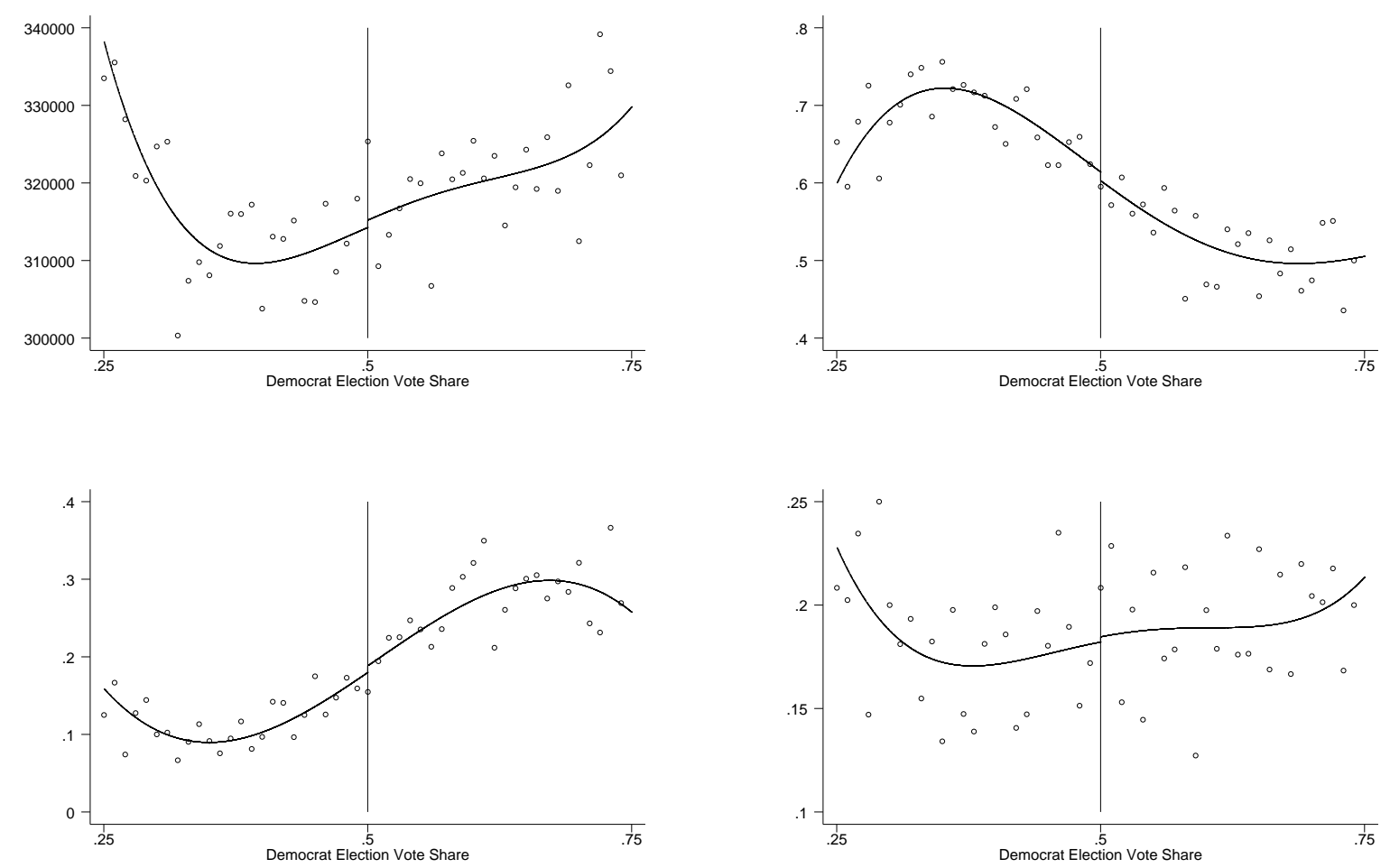

Notes: Panels refer to (from top left to bottom right) the following District Characteristics: voting population, North, South, West. Each point is the average characteristic within intervals 0.01 wide. 
Figure 5: Probability of Democrat Win Election at time t, by Democrat Vote Share at time t-1; and ADA Scores at time t, by Democrat Vote Share at time t-1.

Probability of Democrat Win Election at time t

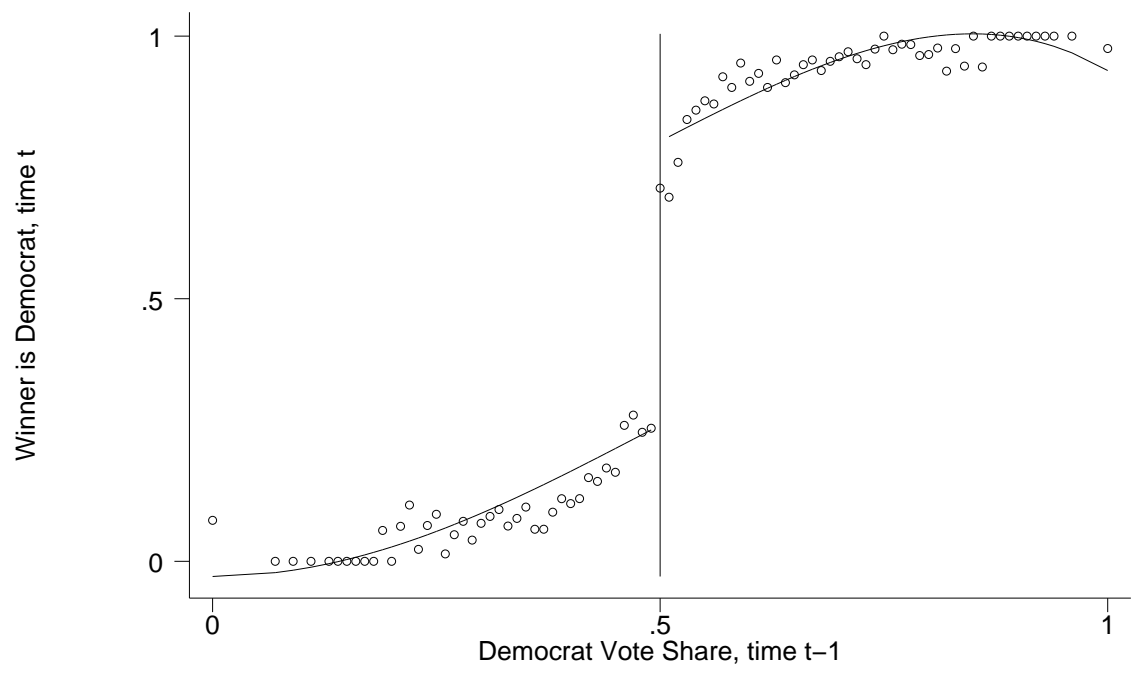

ADA score at time $t$

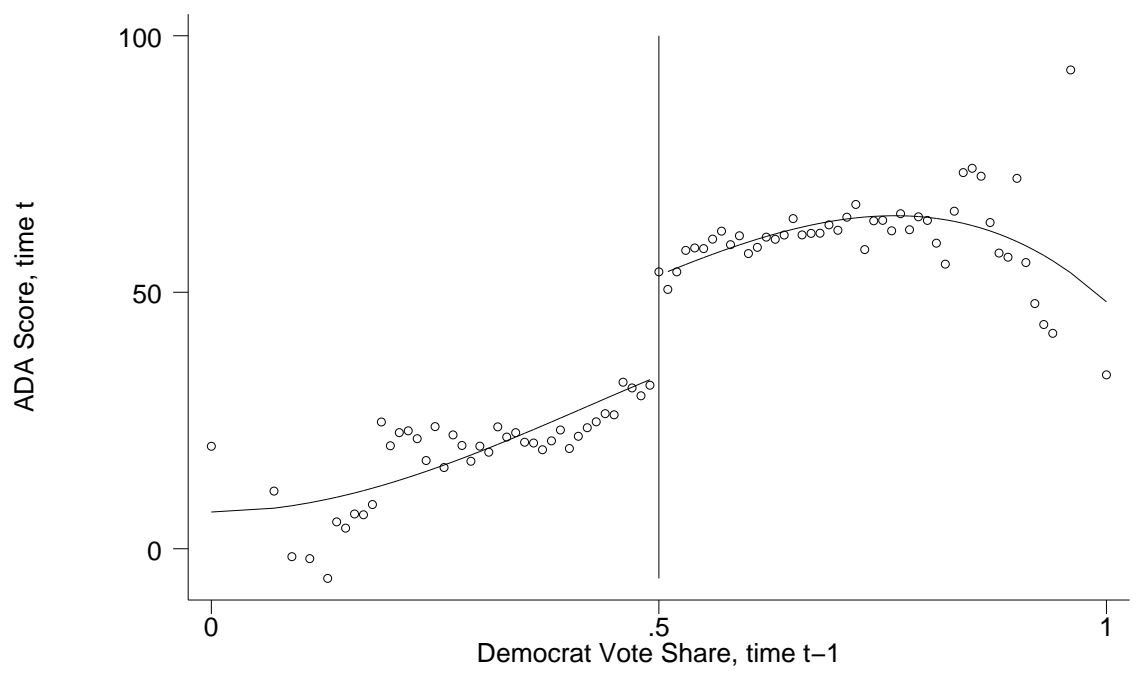

Notes: The top panel plots the probability that a Democrat wins the election at time t against the democrat vote share at time t-1. Each point is the average probability within intervals 0.01 wide. The bottom panel plots the ADA score at time $t$ against the democrat vote share at time t-1. Each point is the average ADA score within intervals 0.01 wide. Time $t$ and $t-1$ refer to congressional sessions. 
Figure 6: Nominate Scores, by Democrat Vote Share; and Probability of Voting Along Party Lines, by Democrat Vote Share

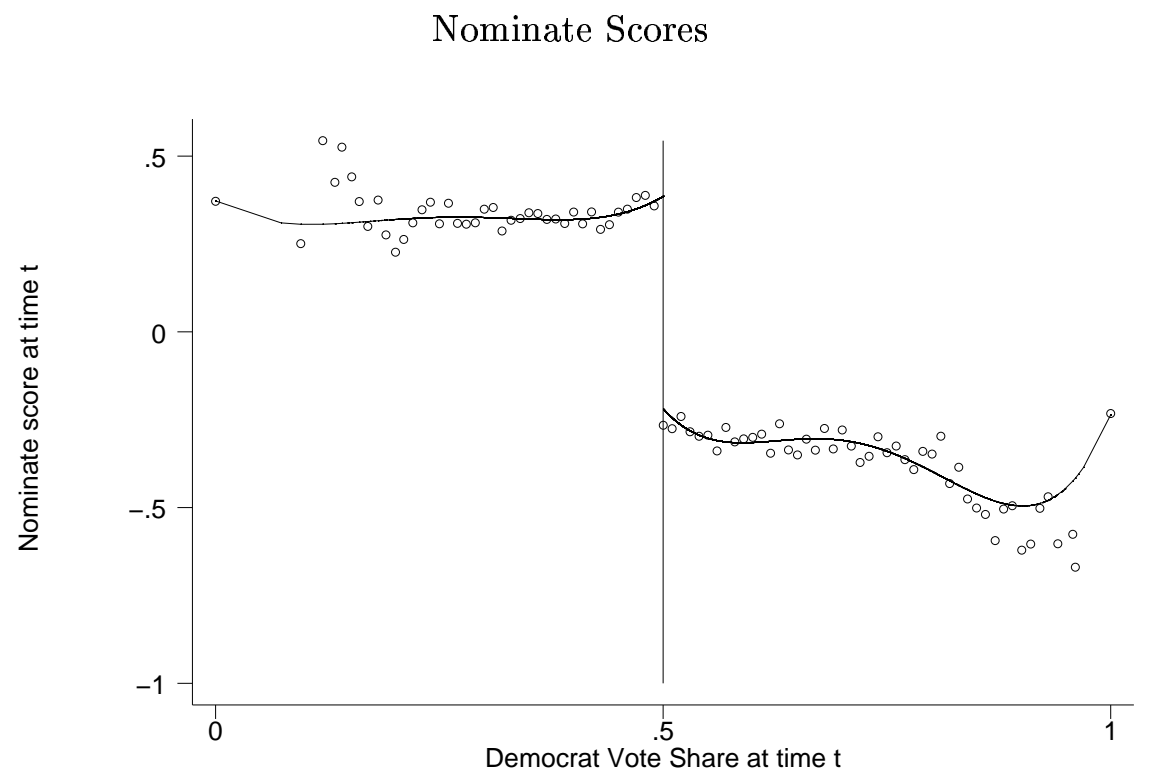

Percent Vote Equal to Democrat Party Leader

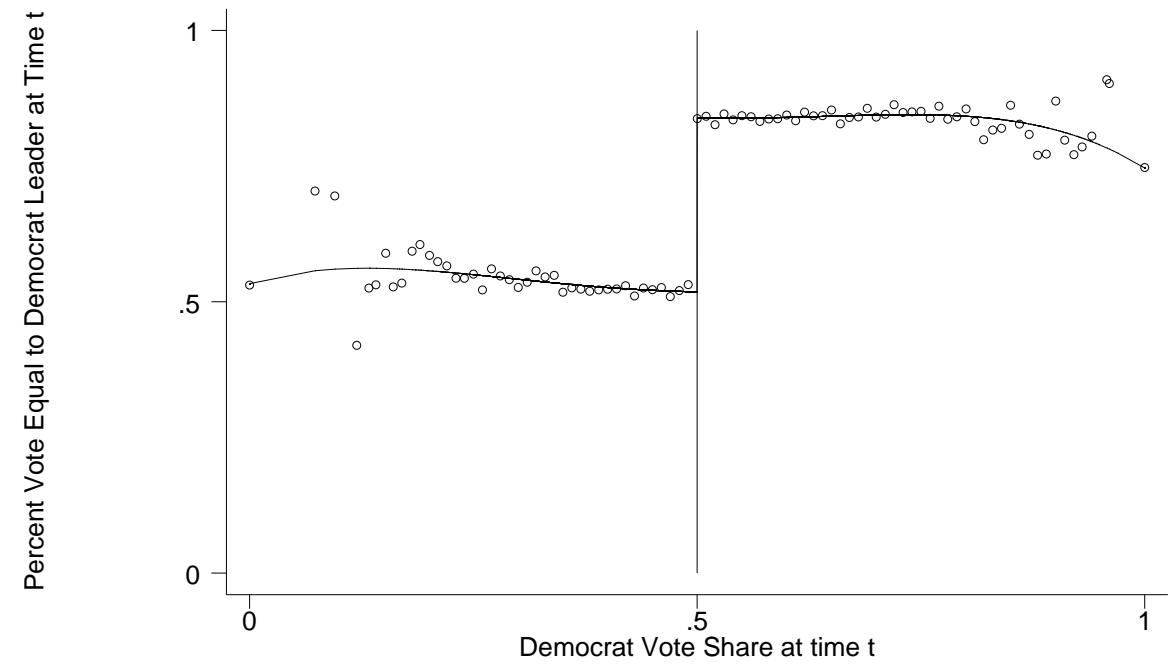

Notes: The top panel plots DW-Nominate scores at time $t$ against the democrat vote share at time t. Each point is the average Nominate score within intervals 0.01 wide. The bottom panel plots the fraction of a representative's votes that agree with the Democrat party leader at time $\mathrm{t}$ against the democrat vote share at time $\mathrm{t}$. Each point is the average fraction within intervals 0.01 wide. 
Figure 7: Liberal Interest Groups Ratings, by Democrat Vote Share. Part 1
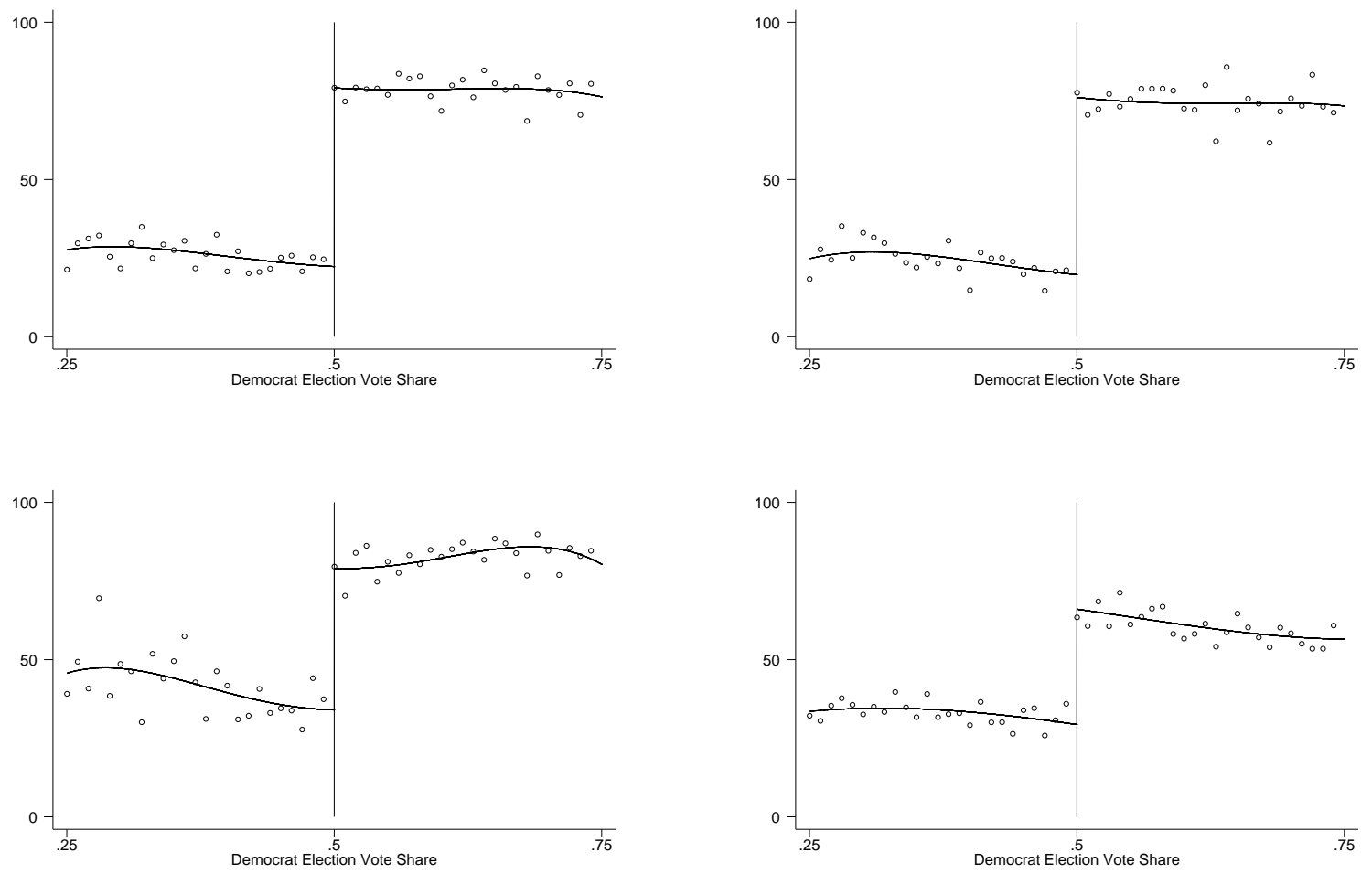

Notes: The top panel on the left refers to ratings from United Auto Workers. The top panel on the right refers to ratings from American Federation of Teachers. The bottom panel on the left refers to ratings from American Federation of Government Employees. The bottom panel on the right refers to ratings from League of Conservation Voters. Each point is the average rating within intervals 0.01 wide. 
Figure 8: Liberal Interest Groups Ratings, by Democrat Vote Share. Part 2
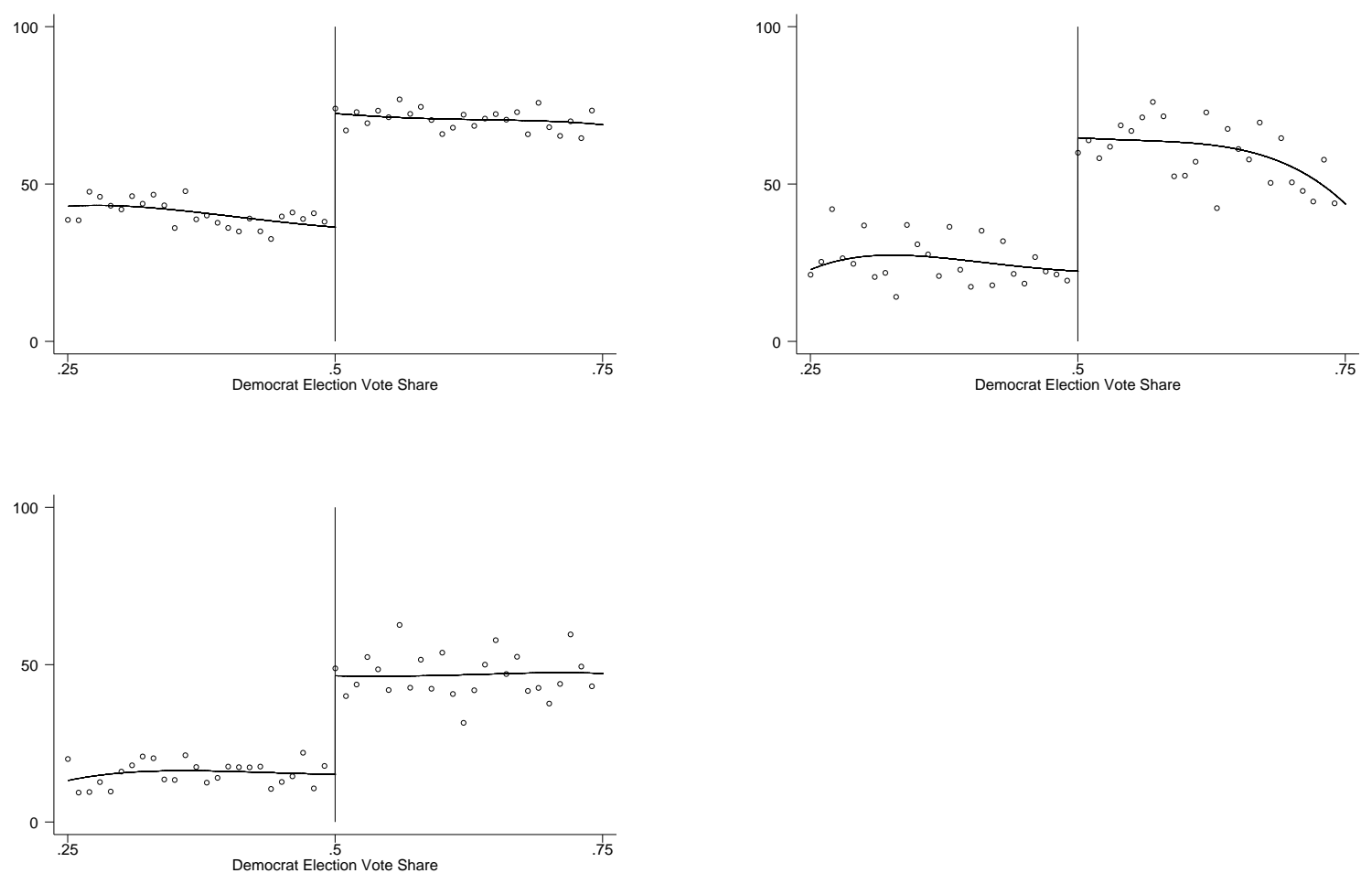

Notes: The top panel on the left refers to ratings from League of Women Voters. The top panel on the right refers to ratings from American Civil Liberties Union. The bottom panel on the left refers to ratings from Taxation with Representation. Each point is the average rating within intervals 0.01 wide. 
Figure 9: Conservative Interest Groups Ratings, by Democrat Vote Share. Part 1
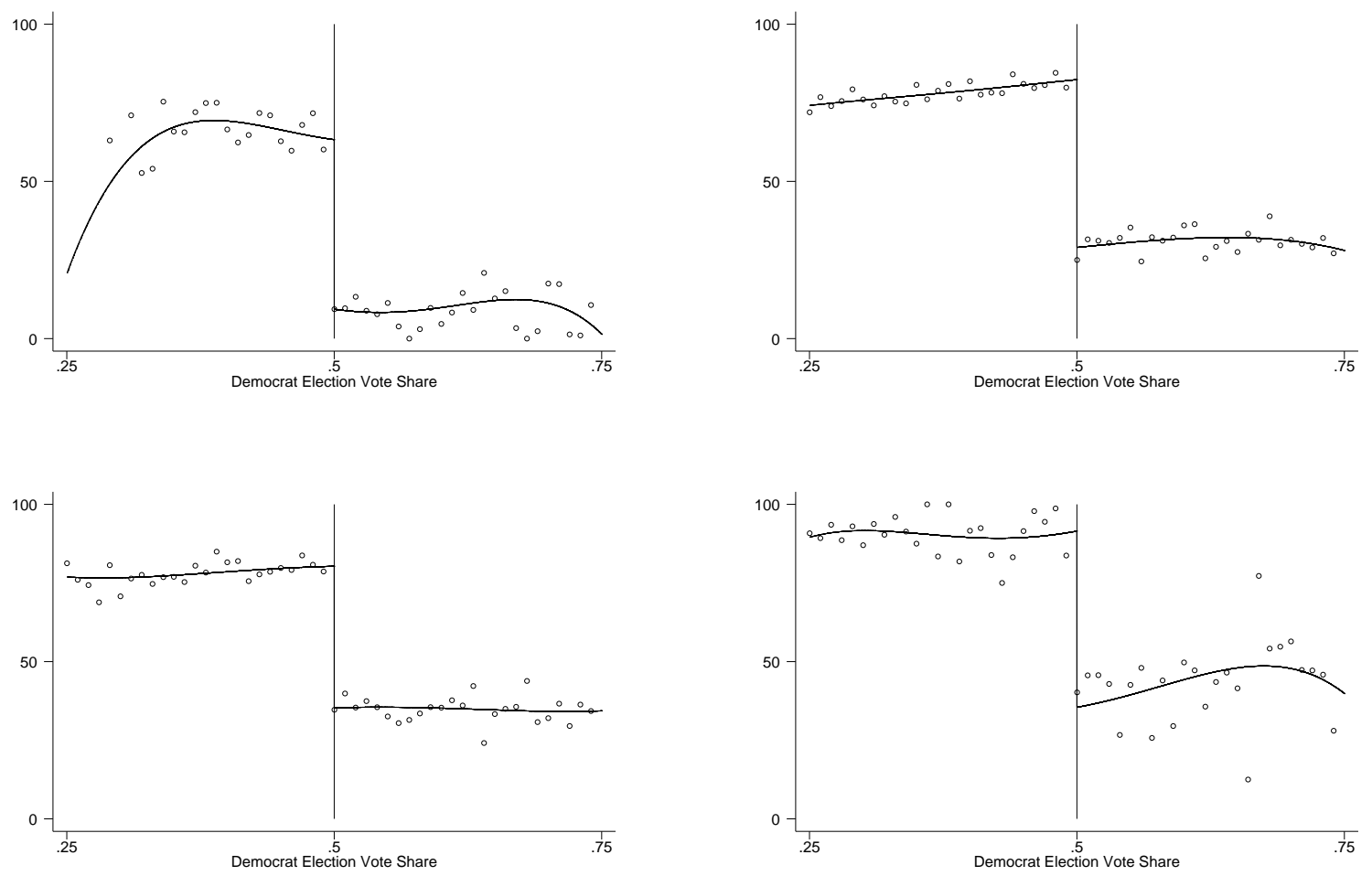

Notes: The top panel on the left refers to ratings from the Lower Federal Spending Support Score. The top panel on the right refers to ratings from the Conservative Coalition. The bottom panel on the left refers to ratings from the Chamber of Commerce. The bottom panel on the right refers to ratings from the Christian Voters Victory Fund. Each point is the average rating within intervals 0.01 wide. 
Figure 10: Conservative Interest Groups Ratings, by Democrat Vote Share. Part 2
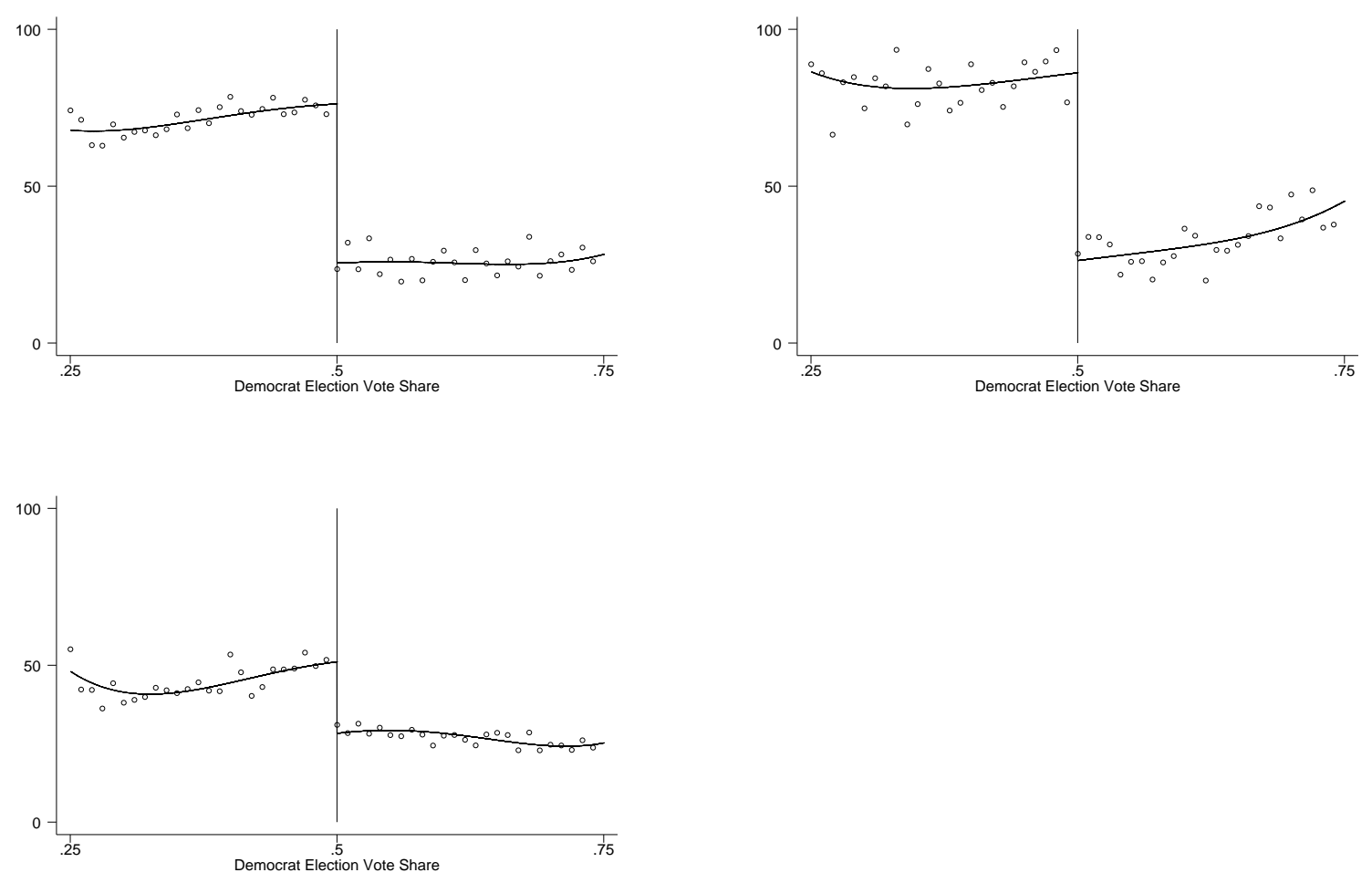

Notes: The top panel on the left refers to ratings from the American Conservative Union. The top panel on the right refers to ratings from the Christian Voice. The bottom panel on the left refers to ratings from the National Taxpayers' Union. Each point is the average rating within intervals 0.01 wide. 
Figure 11: Comparison of Regression Discontinuity Estimates and Regression Discontinuity-IV Estimates, for Alternative Interest Group Ratings

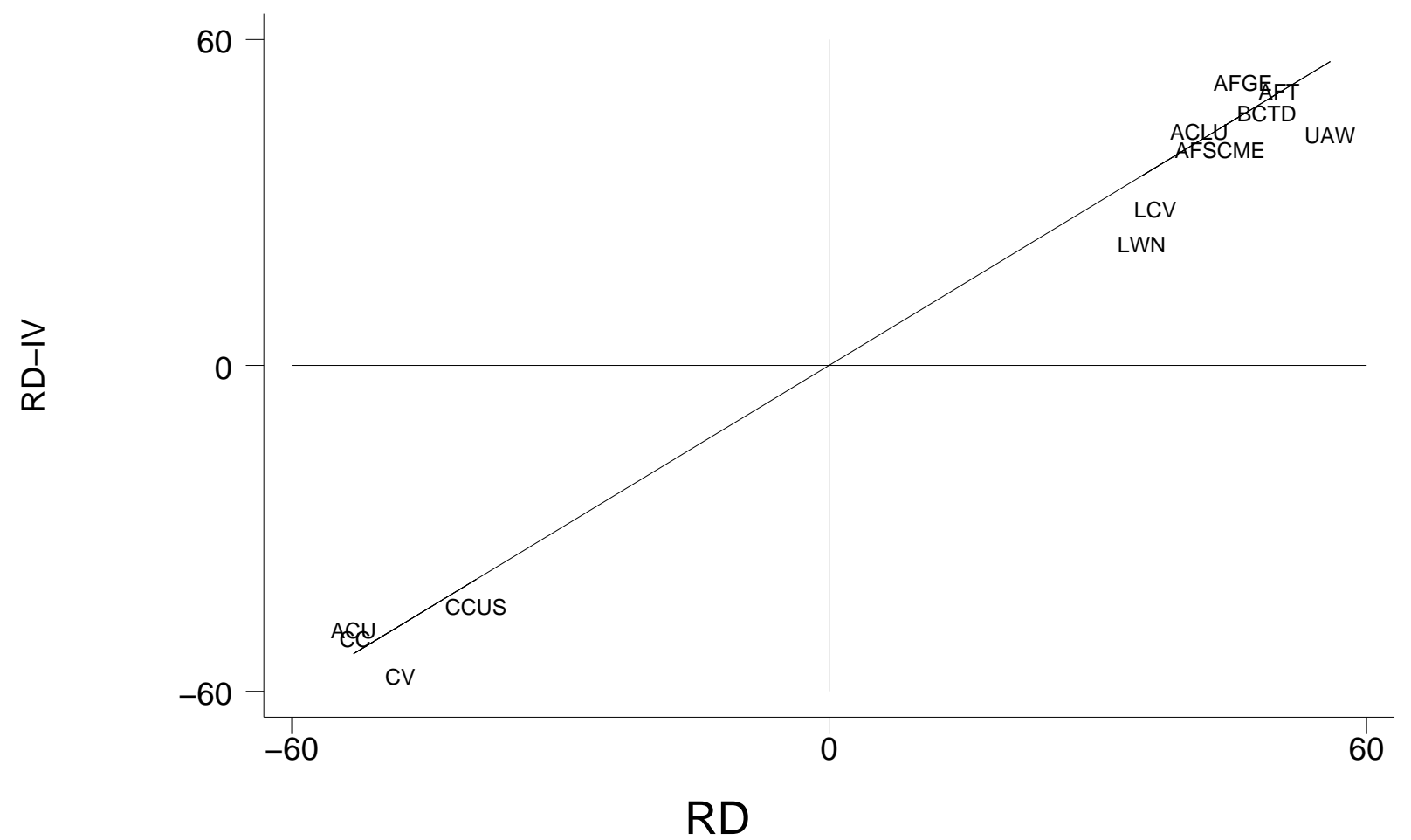

Note : ACLU is Am. Civil Liberties Union; LWV is League of Women Voters; LCV is League of Conservation Voters; AFGE is Am. Fed. Government Employees; AFSCME is Am. Fed. State, County, Mun. Emp.; AFT is American Federation of Teachers; BCTD is AFL-CIO Building and Construction; UAW is United Auto Workers; CC is Conservative Coalition; CCUS is US Chamber of Commerce; ACU is American Conservative Union; CV is Christian Voice. 
Figure 12: Probability of Pro-Choice Votes on Abortion, by Democrat Vote Share

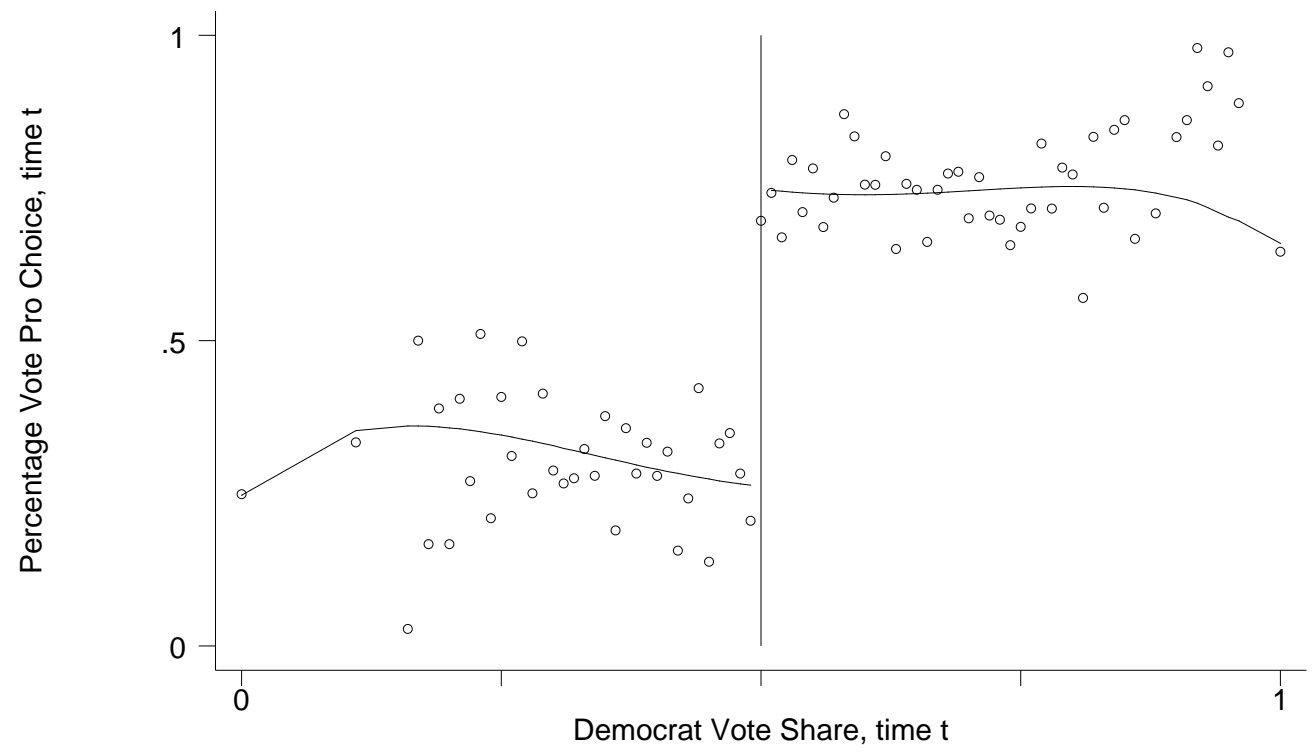

Notes: The figure plots the probability of voting pro choice against the democrat vote share at time t. Each point is the average probability within intervals 0.01 wide. 